\title{
Aplicación del análisis bioclimático a la prescripción arquitectónica
}

\author{
Ricardo Tendero Caballero
}

Artículo

Afiliación: Universidad Politécnica de Madrid, Madrid, España.

E-mail: ricardo.tendero@upm.es

Recibido: 16 de agosto del 2019

Aceptado: 7 de noviembre del 2019

Ricardo Tendero Caballero

Doctor por la Universidad Politécnica de Madrid, arquitecto y arquitecto técnico, actualmente profesor de grado y master oficial en la Escuela Técnica Superior de Edificación en el área de construcciones arquitectónicas, desempeño ambiental y desarrollo sostenible.

\begin{abstract}
Resumen
La habitabilidad en la edificación es una demanda fuertemente implicada en el consumo de energía no renovable, escasa y contaminante. La reducción del consumo y la utilización de fuentes de energía sostenibles hacen necesario explorar procedimientos de análisis eficientes. Se considera el análisis bioclimático como la técnica adecuada para conseguir la optimización de la respuesta del edifico al clima, por lo que se revisan las dificultades existentes para su correcta implantación. Mediante la revisión bibliográfica y la recopilación de iniciativas, se propone una mejora del conocimiento en campos como el aprendizaje mediante el análisis de arquitectura vernácula, la definición correcta de las condiciones climáticas locales, la determinación de los valores de consigna más apropiados para conseguir condiciones de confort interiores, la definición de los patrones de diseño, caracterización bioclimática de edificios, materiales y sistemas constructivos. Asimismo, el desarrollo de estrategias y prácticas constructivas, la estandarización y aplicación rutinaria de métodos de comprobación "in situ" del desempeño bioclimático y la validación de los procedimientos informáticos acreditan la habitabilidad y la forma de concretar este aprendizaje en la regulación, el marco normativo y el establecimiento de condiciones de uso y mantenimiento que rentabilicen la implantación de este análisis bioclimático. Se concluye con la necesidad de aprovechar los avances conseguidos para mejorar el rendimiento de la edificación en su objetivo de conseguir una mejor habitabilidad con un menor consumo de recursos.
\end{abstract}

Palabras Clave: arquitectura bioclimática; habitabilidad; edificación sostenible; análisis bioclimático; estrategia bioclimática.

\section{Application of bioclimatic analysis to architectural prescription}

\begin{abstract}
Currently, the attainment of a liveable environment requires the use of non-renewable, scarce, and pollutant energy. In order to decrease the consumption of energy as well as increase the use of renewable energies, it is necessary to explore procedures for efficient analysis. Bioclimatic analysis is the appropriate technique to optimize the response of a building to climate. Consequently, the article examines the existing difficulties to its smooth/correct implementation. Through the gathering of initiatives stemming from the author's technical and professional activity as well as from an extensive bibliographic review, the article introduces an improvement to the knowledge of the multiple fields that define the discipline of bioclimatic analysis. Specifically, the analysis of vernacular architecture, the suitable definition of the local climatic conditions, the identification of the most appropriate reference values to reach indoor comfort, and the definition of patterns for the design and bioclimatic characterization of buildings materials and constructive systems. In addition, the article includes the development of building strategies and practices, the standardisation and application of means of verification "in situ" of the bioclimatic performance of a building, and the validation of computerised processes that predict the degree of habitability of a building. Finally, the knowledge acquired in the prior fields is incorporated in the regulatory framework as well as the establishment of operating conditions and maintenance requirements that capitalise on the implementation of the aforementioned bioclimatic analysis. The article establishes the need to embrace the progress made in these fields to improve the performance of buildings and achieve a superior habitability with a lower consumption of resources.
\end{abstract}

Keywords: bioclimatic architecture; habitability; sustainable building bioclimatic analysis, bioclimatic strategies. 


\section{Antecedentes}

a búsqueda de alojamiento ha acompañado el desarrollo humano desde edades muy tempranas de su evolución. Ya sea ocupando espacios naturales o conformando recintos, los humanos consiguen encontrar una respuesta al clima. Esta necesaria empatía entre el clima y la habitabilidad de la arquitectura es lo que denominamos como arquitectura bioclimática, empleando este término en la acepción que desarrollan, entre otros, los hermanos Olgyay en los años 60, que recoge una tradición que considera las peculiaridades del clima en la prescripción arquitectónica (Olgyay, 1998). Desde hace más de 12.000 años, la elaboración de refugios permanentes, capaces de modificar las condiciones higrotérmicas del entorno para aproximarlas a aquellas que hacian a sus moradores más eficientes, está asociada a la progresiva sustitución de actividades itinerantes como la caza y la recolección, por otras sedentarias como la agricultura y la ganadería (Harari, 2014).

Todo este aprendizaje, basado en sucesivas pruebas y la consiguiente corrección de los errores cometidos, va depurando las técnicas y el diseño más adecuado para cada lugar y el uso de los materiales y las tecnologías posibles con el tiempo disponible para construirlos y disfrutarlos, replicando por mímesis las mejores soluciones. Muchos de los logros conseguidos se siguen empleando en la actualidad y son objeto de estudio para conocer mejor culturas ancestrales y buscarles acomodo en nuestro sistema de producción edilicia contemporánea (Figura 1).

Figura 1. La arquitectura troglodita tradicional de Guadix (Granada-España) (1 y 2) mantiene su uso residencial en la actualidad encalando sus parámetros y añadiendo cuerpos exteriores (3) o aplicando esta estrategia a nuevos edificios (4) donde puede combinarse con protecciones solares vegetales y pavimentos de cal y arcilla para habilitar espacios exteriores (5), como en este hotel en Vejer de la Frontera (Cádiz-España).

Fuente: Elaboración propia.

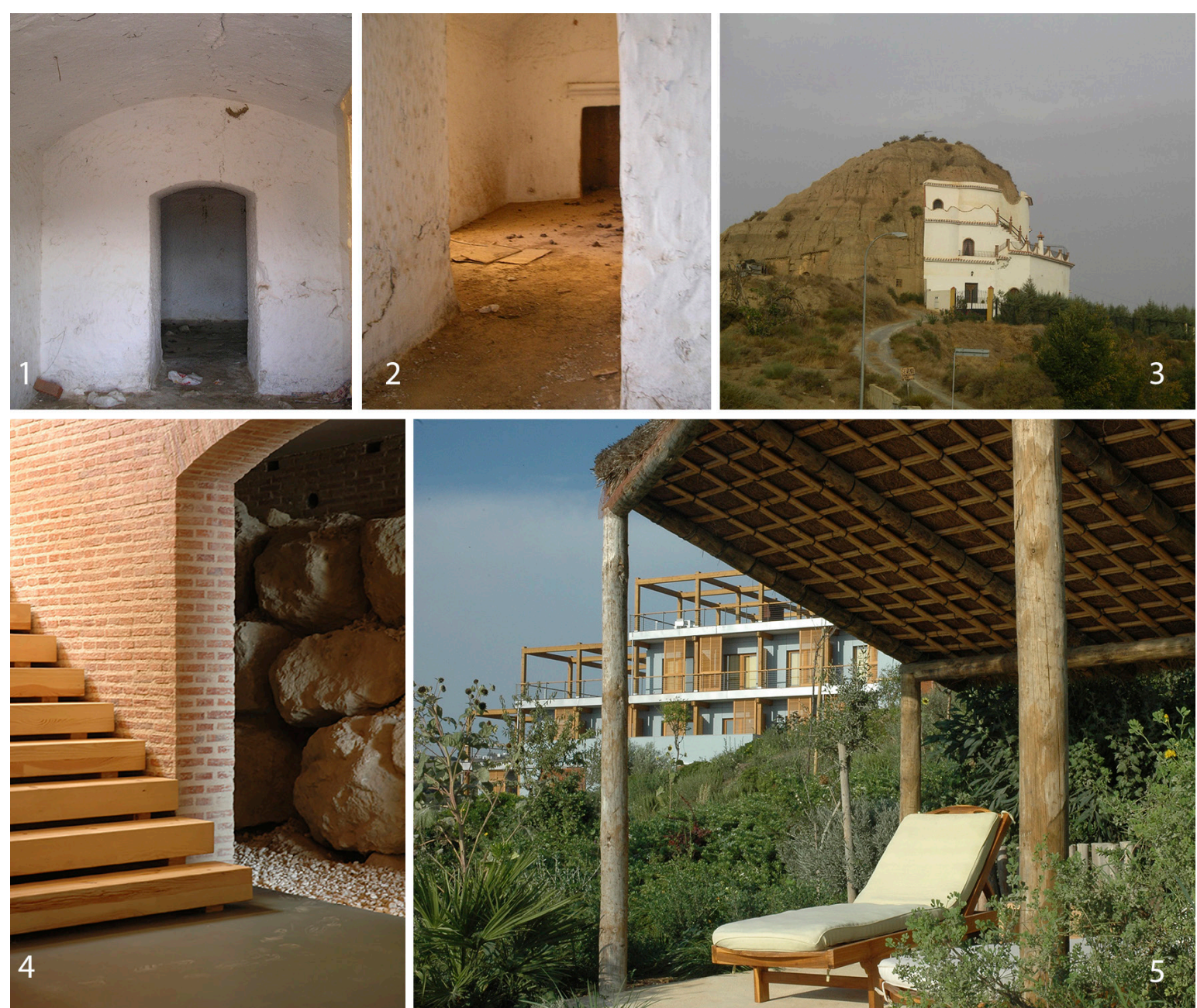

El análisis bioclimático, ya desde sus inicios, estudia las construcciones antiguas para justificar su emplazamiento, sus cualidades, sus limitaciones y su evolución (Oliver, 1978). Las necesidades de energía han movilizado el ingenio humano para conseguir la habitabilidad requerida mediante sistemas que aprovechen energías naturales, como la solar, la hidráulica o la eólica, la ventilación o el aislamiento. Las glorias, como evolución del hipocausto romano, o los invernaderos, que permiten aportar energía al edificio, bien por la combustión de la biomasa, bien reteniendo la energía merced al cambio de longitud de onda cuando esta es emitida por la masa interior, son ejemplos de ello (Butti \& Perlin, 1985).

La huida en avalancha hacia los núcleos urbanos genera problemas de salubridad y eficiencia, que hacen necesaria la ordenación de la ciudad y sus construcciones (planeamiento), el desarrollo de limitaciones a los procesos de hacinamiento y la dotación de los servicios mínimos (ordenanzas) y el desarrollo de arquitecturas saludables. La praxis de la arquitectura se define entre dos extremos. En uno de ellos, que se denominará como integrado, cada elemento arquitectónico se ocupa de atender 
varias funciones del edificio, de forma que los sistemas constructivos, la geometría, los materiales, la exposición o la disposición de los espacios se alinean para conseguir la "venustas, firmitas y utilitas" enunciadas por Vitruvio (1786), así como la "comoditas" propuesta por Alberti (1582) y a las que se permitirá añadir la mesura y economía que Palladio (1797) evoca en el proemio a sus cuatro libros: "Así se aprenderá poco a poco a desterrar los abusos, caprichos, invenciones bárbaras y gastos superfluos".

En el otro extremo, la arquitectura consigue las prestaciones requeridas mediante sistemas independientes, en lo que podemos denominar como arquitectura disociada. Mientras unos componentes se ocupan de soportar los esfuerzos, otros los embellecen, otros procuran que tengan unas condiciones de habitabilidad adecuadas y, finalmente, otros los protegen y le dan durabilidad. La arquitectura normalmente no se adscribe completamente a uno u otro modelo, aunque por desgracia es frecuente observar cómo algunos edificios contemporáneos, en un ejercicio suicida de bombero pirómano, "embellecen" los edificios con sistemas constructivos que obligan a disponer materiales, equipos y mecanismos muy costosos y de alto consumo energético para corregir un "disconfort" que podría haberse evitado.

Lejos de esta última opción, muchos edificios reflejan el trabajo responsable del arquitecto para conseguir una racional relación entre la edificación y el clima. Más allá de la arquitectura de autor 0 de estilo, de las apetencias de sus promotores por evidenciar un carácter o un estatus o de la influencia monopolística de algún sector industrial o económico, la arquitectura actual nos ofrece una gran variedad de soluciones integradas a la habitabilidad.

La recopilación de buenas prácticas para favorecer el bienestar en los edificios es, durante una buena parte de nuestra historia, la única fuente de aprendizaje. Estudios puntuales y fragmentarios complementan este gran catálogo que cuenta con ejemplos muy antiguos, como el recopilado por Marco Vitruvio Polión en el siglo I antes de Cristo (Vitruvio, 1786) hasta otros casi contemporáneos desarrollados como recomendaciones regionales genéricas, como es el caso de Europa (Lewis \& Brophy, 2011) o los trópicos. Esta tendencia se materializa en sistemas de evaluación de las cualidades medioambientales de los edificios con voluntad de ser aplicados globalmente como son Leed o Breeam, otros que buscan una mayor adaptación local, como Verde (España), Casbee (Japón) y Edge (Costa Rica), o los focalizados en la eficiencia energética como Passivhaus o Minergy, por poner solo algunos ejemplos.

Lagran crisis en elabastecimiento de combustibles en losaños 70 motivauna bienfundada preocupación por la dependencia externa y la carestía de energía, desarrollándose tecnologías de bajo consumo en energías no renovables, aprovechando hasta el límite de sus capacidades los sistemas de captación y disipación de energía local gratuita, y limitando el uso de procesos muy demandantes de energía. En edificación son notables las experiencias que se llevan a cabo en varios centros universitarios estadounidenses en los que se realizan seminarios como la "Sesión en mangas de camisa. The responsive House", en el Departamento de arquitectura del MIT para analizar tecnologías de bajo impacto con capacidad de respuesta en la construcción de viviendas (Allen, 1978) o la recopilación de buenas prácticas en 1977 en Estados Unidos (Watson, 1985) y en 1978 en Francia (Bardou \& Arzoumanian, 1981). La evolución del conocimiento y su divulgación y la proliferación de los centros donde este se crea dan pie al desarrollo de procedimientos de prescripción y peritación de las condiciones de bienestar en los edificios (Figura 2). Muy notables en este sentido son los estudios de Olgyay (1998), Givoni (1969), Mazria (1979) o Fanger (1970).

Este nuevo planteamiento se consolida en procedimientos automatizados que peritan una gran cantidad de opciones para seleccionar la más adecuada y anticipar los consumos estimados. La inexactitud de estos procedimientos de cálculo exige replantear sus algoritmos de transmisión del calor, pero sobre todo la mejora de la caracterización de los sistemas constructivos, un mejor conocimiento de las condiciones climáticas, de los parámetros de confort asociados a las demandas del usuario y la capacidad de captar y disipar la energía.

Sin el afán de ser exhaustivo, se pretenden enunciar algunas de las cuestiones en las que es preciso, para una correcta prescripción y peritación de la arquitectura, integrar el análisis científico al análisis bioclimático, para dar así respuesta a la actual 
Figura 2. Esquema de toma de decisiones para conseguir las condiciones de habitabilidad interior y los parámetros implicados en este proceso.

Fuente: Elaboración propia. aplicación irreflexiva de los procedimientos predictivos y a las iniciativas que se centran en atender a la iconografía que acompaña al desarrollo de una arquitectura pretendidamente bioclimática. Así se considera que, aplicándolos a cada lugar, clima 0 situación socioeconómica, debe estimularse el estudio de:

1. Las arquitecturas ancestrales

2. El clima local

3. Las condiciones de confort y consigna

4. La caracterización bioclimática de edificios, materiales y sistemas constructivos

5. El diseño y desarrollo de estrategias y prácticas constructivas

6. Los métodos de comprobación "in situ" del desempeño bioclimático

7. La validación de los procedimientos informáticos que acreditan la habitabilidad

8. La regulación y el marco normativo

9. Las condiciones de uso

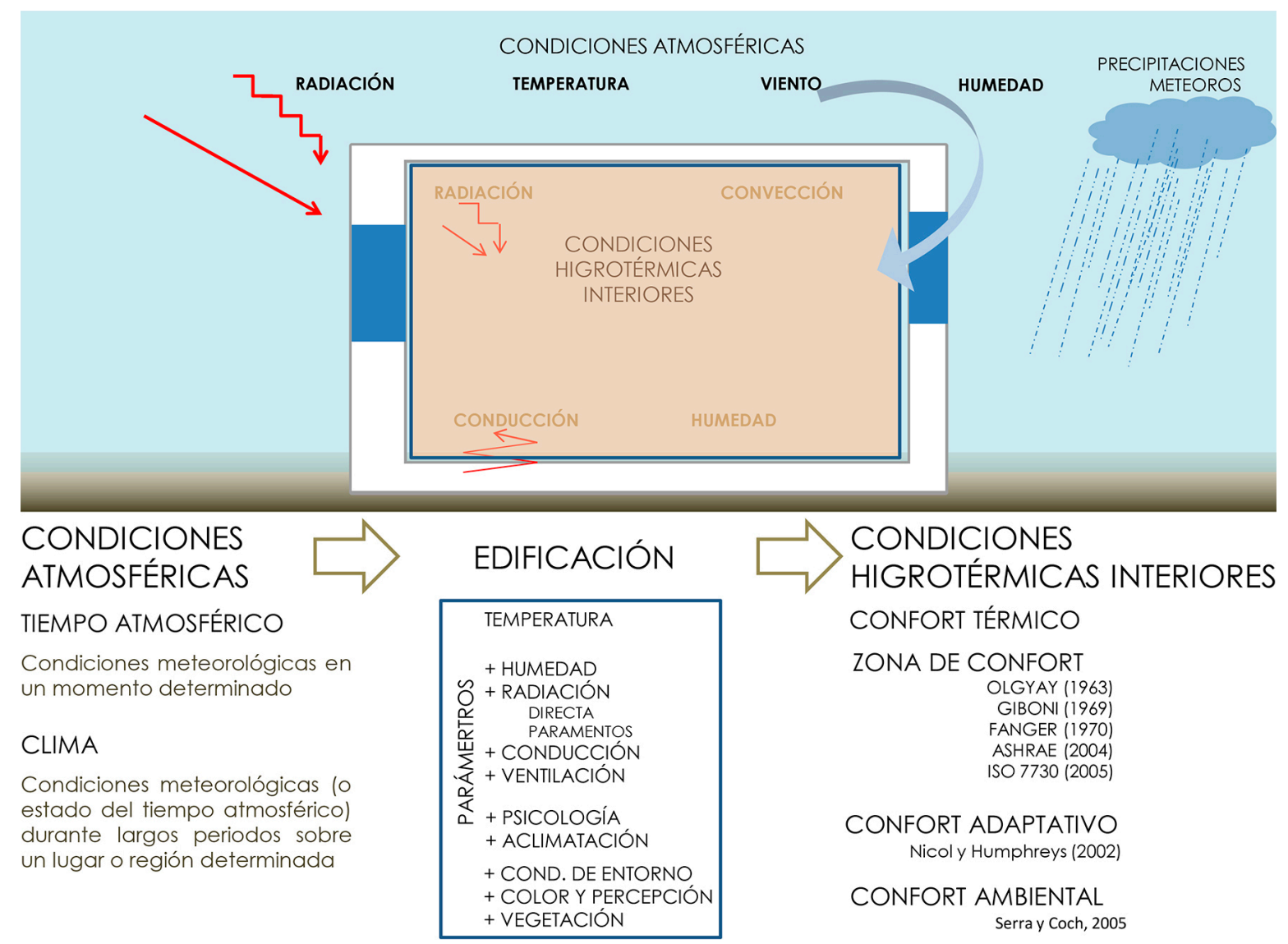

\section{Campos de actuación prioritaria}

\section{Estudio de arquitecturas ancestrales}

La arquitectura es una tecnología útil en donde se busca la belleza. Esto hace que sea un campo poco apropiado para la experimentación descontextualizada. Históricamente, los avances se han realizado paulatinamente y apoyándolos en la tradición con la incorporación prudente de nuevas aportaciones. Cuando no ha sido así, las experiencias han conducido al deterioro, la disfuncionalidad o la ruina de la edificación. De ahí que los tratados clásicos de arquitectura hayan defendido las aportaciones de sus autores, integrándolas en una pretendida o real tradición edificatoria (Vitruvio, 1786; Alberti, 1582; Palladio, 1789).

Con diversas denominaciones como vernácula, popular, tradicional 0 , en algunos lugares, patrimonial, la arquitectura definida por la sedimentación de las experiencias locales, muchas veces a partir de modelos o tipos importados, es una fuente de conocimiento que permitirá a un observador atento aprender por experiencia ajena las mejores prácticas edilicias. La aplicación en otros lugares y circunstancias exige acompañar las observaciones de un análisis apropiado para encontrar estrategias adecuadas para resolver los grandes problemas actuales con estrategias adecuadas, y así poder replicarlas en soluciones adaptadas a cada situación, como puede ser, por ejemplo, para conseguir refrigerar en climas cálidos mediante el enfriamiento pasivo (Esteban, 1986). 
Este análisis se aplicará a la descripción de las condiciones atmosféricas en las que previsiblemente el edificio se encontrará inserto, las necesidades de los usuarios y la definición de las estrategias que pongan en valor los recursos naturales o bioclimáticas, como ejemplo puede considerarse una aplicación a Bubión (Granada -España) (Luxan et al., 2010). La ocupación de territorios en climas muy extremos y con unos recursos limitados, como es el caso de este valle al sur de Granada, exige a las edificiaciones una gran eficacia en su diseño y en los sistemas constructivos empleados. En esta zona todos los meses del año se experimentan condiciones a veces muy altas de demanda de energía, para alcanzar condiciones de habitabilidad. Sin embargo entre los meses de junio y septiembre es necesario ocasionalmente disipar el exceso de calor en el interior de los edificios.

Para adaptarse a estas condiciones los edificios evitan la exposición al norte adosándose a la ladera, maximizan la exposición sur para la captación de energía solar en periodos fríos y buscan la máxima ocultación en periodos cálidos. La configuración urbana y arquitectónica es acorde a estos principios y estrategias. Así, para habilitar los espacios próximos y evitar las fuertes nevadas y los vientos fríos, se ubican con orientación sur, se establecen espacios semiexteriores próximos protegidos como zaguanes, soportales 0 tinaos y se aprovechan las solanas artificiales de uso compartido denominadas terraos en las cubiertas de los edificios (Figura 3). Las aportaciones suplementarias de energía se producian históricamente por la estabulación en planta baja del ganado y la quema de madera en hogares interiores abiertos con grandes chimeneas al exterior.

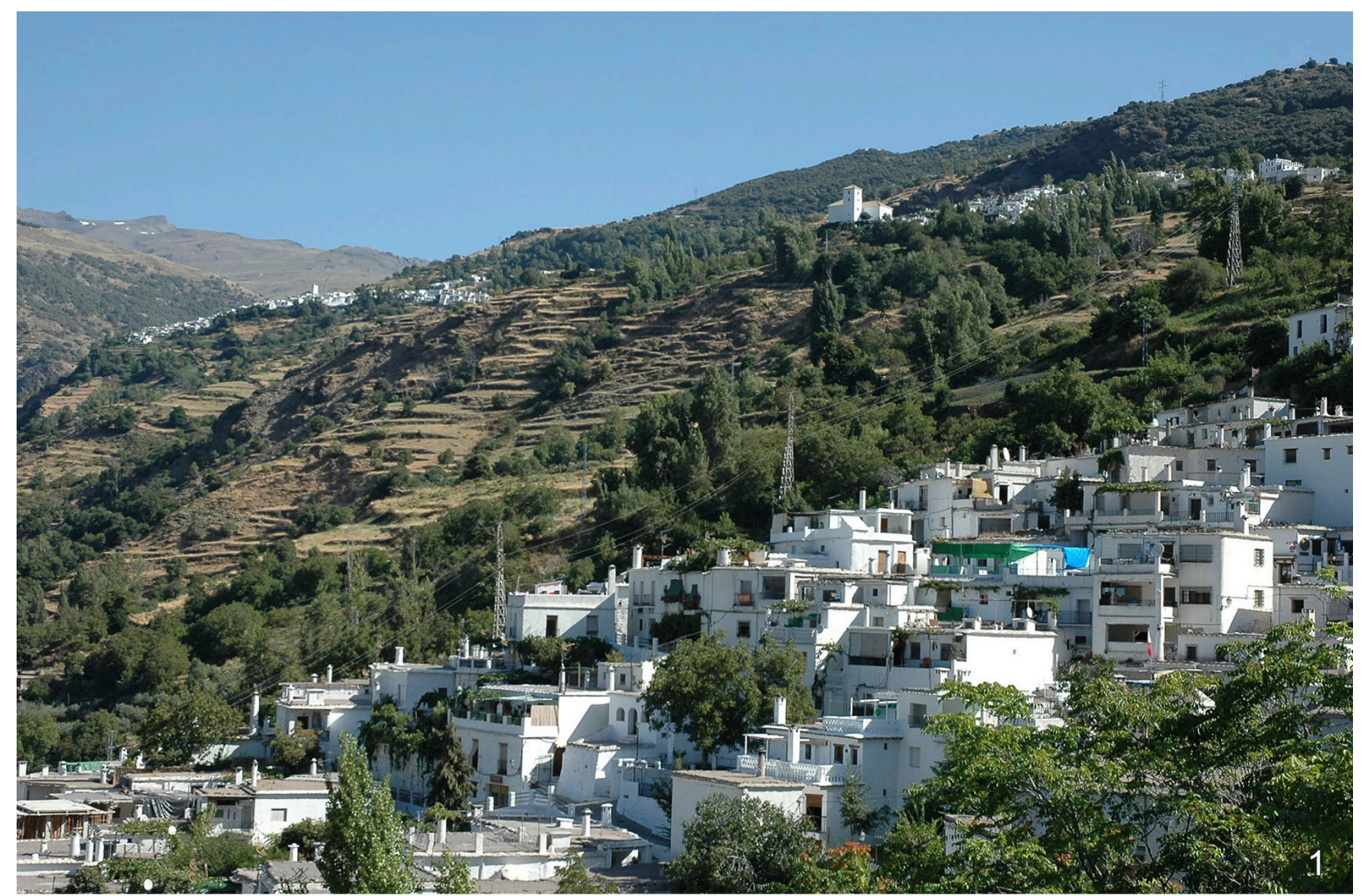

Figura 3. La ubicación en la ladera sur permite una buena exposición solar, aprovechar la inercia térmica del terreno y la protección de los vientos fríos del norte. La disposición escalonada permite el uso de las terrazas ("terraos") como solanas de uso privativo (1, 2 y 3). En el viario se configuran espacios semi-exteriores públicos para protegerse del sol y la nieve (3 y 4). Fuente: Elaboración propia.
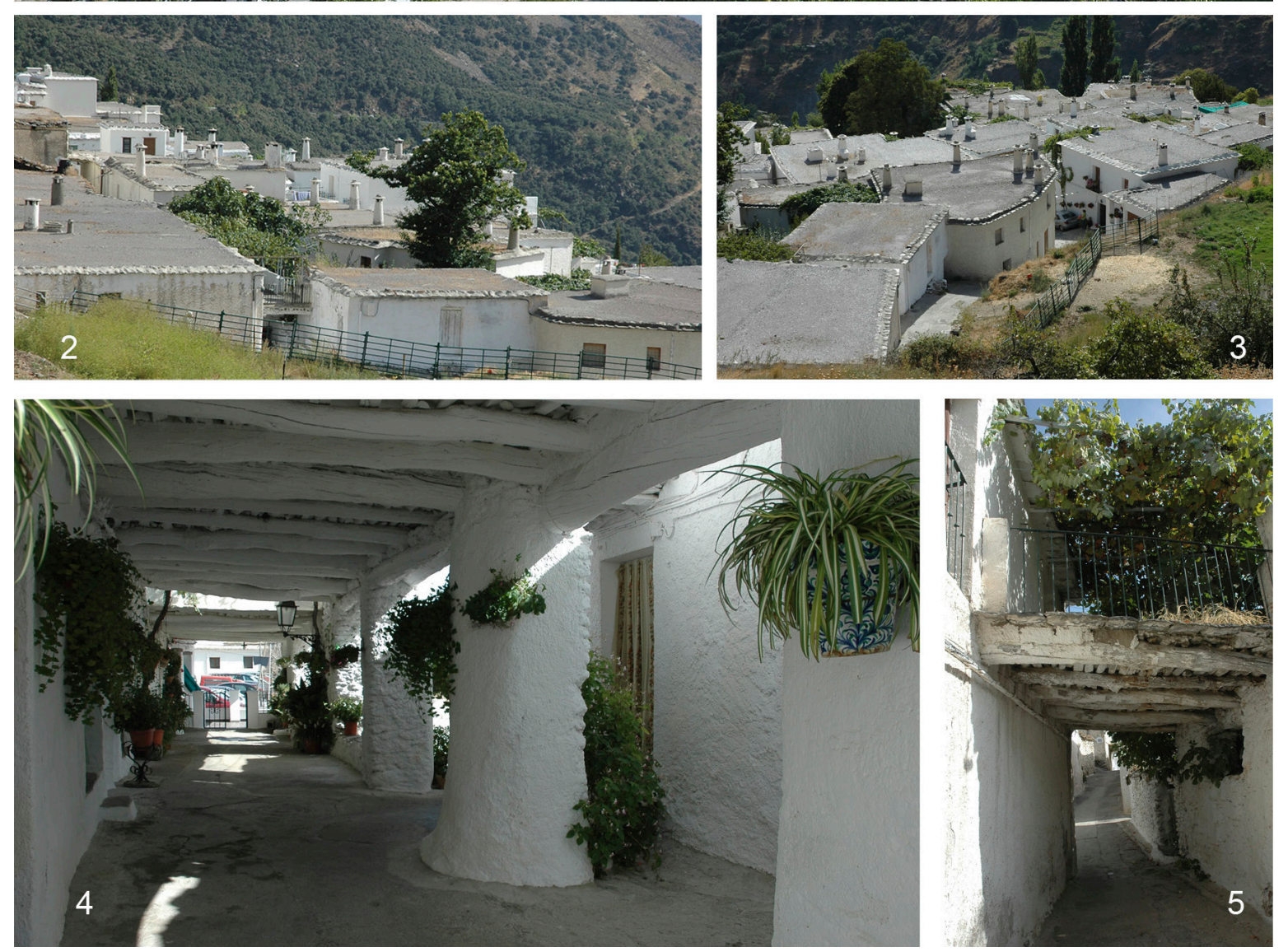


\section{Determinación del clima local}

La adaptación climática de las edificaciones se decanta en la arquitectura tradicional con el paso de las generaciones. La rápida ocupación de territorios, los nuevos tipos de edificios o la sustitución de los valores ancestrales por las modas o modos contemporáneos hace que se abandone la mímesis y la normalización espontánea para determinar la adaptación al clima de nuevas iniciativas edilicias mediante la comprobación de esta respuesta. La búsqueda de una correcta definición del clima en su aplicación a la arquitectura se observa desde las primeras iniciativas de análisis bioclimático. Es notable la caracterización del clima y la conformación de categorías climáticas de Olgyay en 1968 (Olgyay, 1998) o en las zonas de vida de Holdridge en 1979 (Holdridge, 2000).

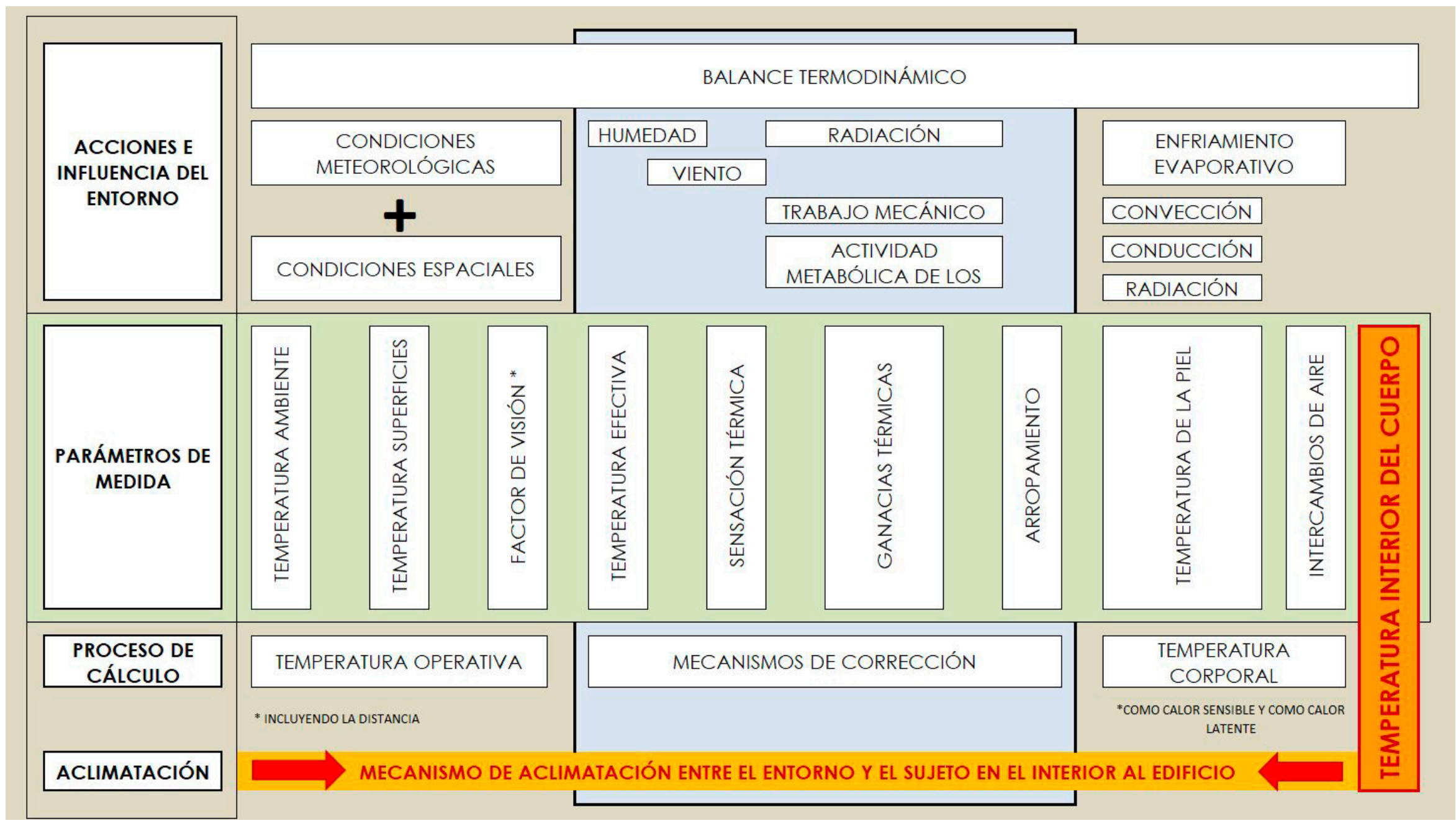

Figura 4. Esquema de los factores que afectan a la percepción de la temperatura y sus distintas acepciones cuando se aplican a determinar la temperatura operativa, incorporar mecanismos de corrección o a establecer la temperatura corporal que va asociada a las demandas metabólicas.

Fuente: Elaboración propia.
El análisis bioclimático, muy difundido en arquitectura, tiene notables aplicaciones en la definición de los biotopos, como la combinación de condiciones tan diversas como las hidrológicas, fenológicas (Almorox et al., 2004), edáficas, climáticas, vegetales, faunísticas; la incidencia en las patologías (Oger, Buffet \& Kestemont, 2005); las paisajísticas que le suman aspectos culturales y la actividad antrópica en general o la morbilidad (Gil \& Olcina, 1999), de ahí que, a pesar de estar aún poco explorada, la interdisciplinaridad sea una de sus principales fuentes de conocimiento. Los parámetros climáticos que deben considerarse en edificación son muy variados. Es importante reconocer las temperaturas medias de las máximas y de las mínimas del lugar o la combinación de humedad y temperatura. En ocasiones deben considerarse los valores extremos mientras que en otras ocasiones pueden ser más significativos los valores medios. La pluviometría es determinante para la recarga de humedad y debe ser matizada con la evapotranspiración. La radiación directa, difusa o reflejada, y su ángulo de incidencia son fundamentales para conocer la capacidad de captación de energía. La velocidad y dirección del viento pueden ser determinantes para la disipación de energía. Todos estos parámetros deben ser considerados conjuntamente en función de su influencia en la habitabilidad y el bienestar higrotérmico (Figura 4). 
En los promedios de los valores climáticos parece manifestarse un sesgo hacia un incremento de la temperatura en núcleos urbanos (AEMET, 2015), en el que se suman factores como la isla de calor urbana (Lorente, 1930) o la evolución global de las temperaturas (Olcina, 2006a). La caracterización del clima local, cuando se dispone de una estación meteorológica de referencia, suele realizarse con los valores medios. Este clima medio no refleja los valores singulares o efemérides y amortigua los valores extremos, por lo que no representa las condiciones en las que se encontrará realmente el edificio (Olcina, 2006b; Fernández, 1996).

Las edificaciones han de aclimatarse a su uso en cada momento 0 , dicho de otro modo, a series de valores climáticos tal y como realmente se producen, por lo que para comprobar que la arquitectura, las estrategias bioclimáticas empleadas, los equipos mecánicos y los mecanismos de accionamiento son capaces de aclimatar los espacios, se hace preciso establecer un clima de referencia que recoja todas las circunstancias climáticas en las que se encontrará el edificio (Godoy, 2012). Los climas así obtenidos son arbitrarios y no estiman bien los consumos medios o estacionales del edificio. La comparación de los periodos (horas) y de las necesidades de energía (grados-hora) en los que se producen superaciones de umbrales en distintos climas de referencia y los valores medios en una década, pone de manifiesto que hay notables diferencias entre diferentes climas de referencia y los valores registrados (Figura 5) o la gráfica comparada de las temperaturas mediana, mínima y máxima absoluta para diferentes climas de referencia y valores promedio (Figura 6).

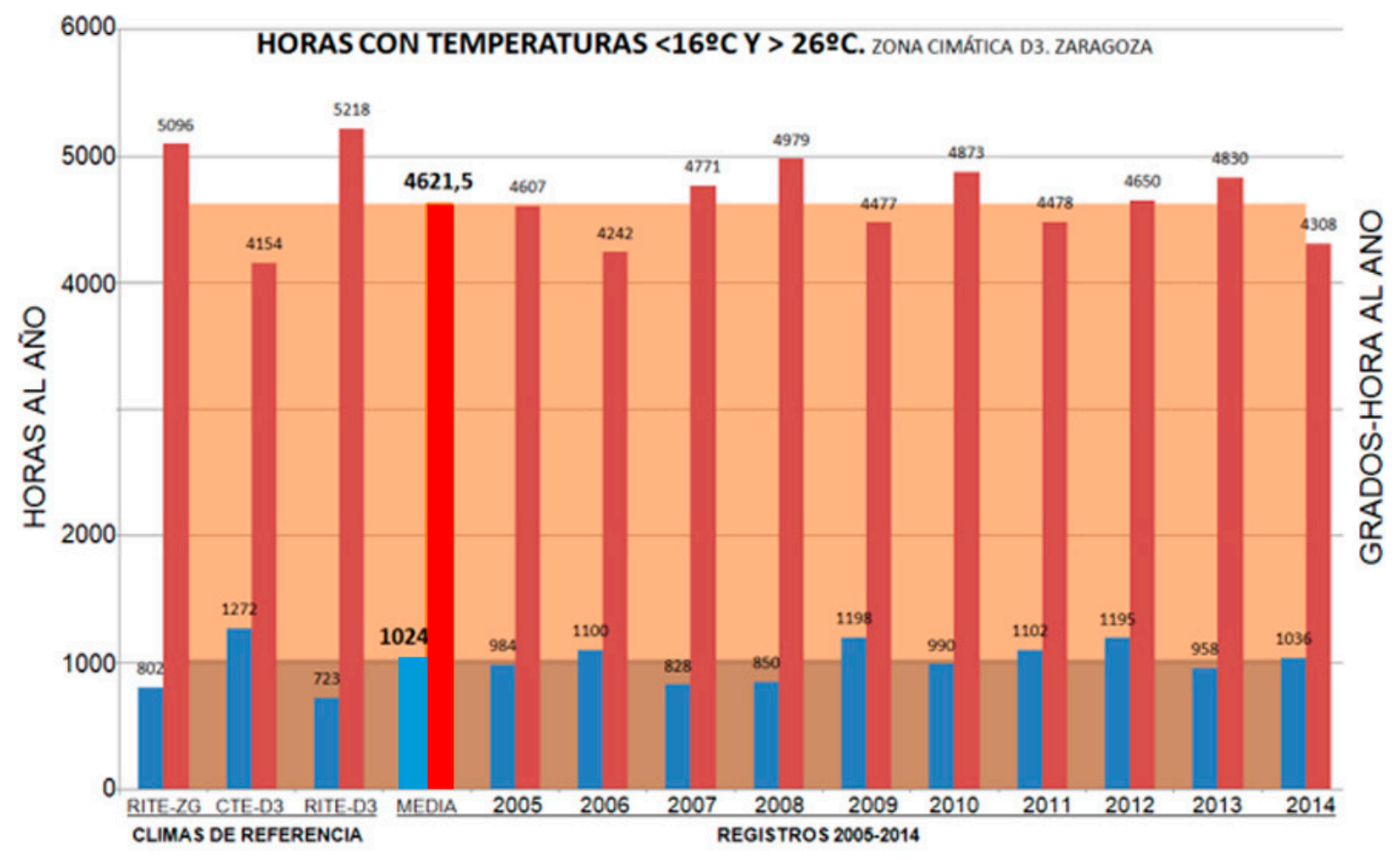

y grados hora (abajo) en que se superan los $26^{\circ} \mathrm{C}$ y en las que no se alcanzan los $16^{\circ} \mathrm{C}$ en los climas de referencia asignados a la ciudad de Zaragoza, como son el asignado por el RITE (RITE ZG) y, para la zona D3, el asignado por el Código Técnico de la Edificación (CTE D3) y por e RITE (RITE D3), así como los valores registrados en Zaragoza entre los años 2005 y 2014 y su promedio anual.

Fuente: Elaboración propia.

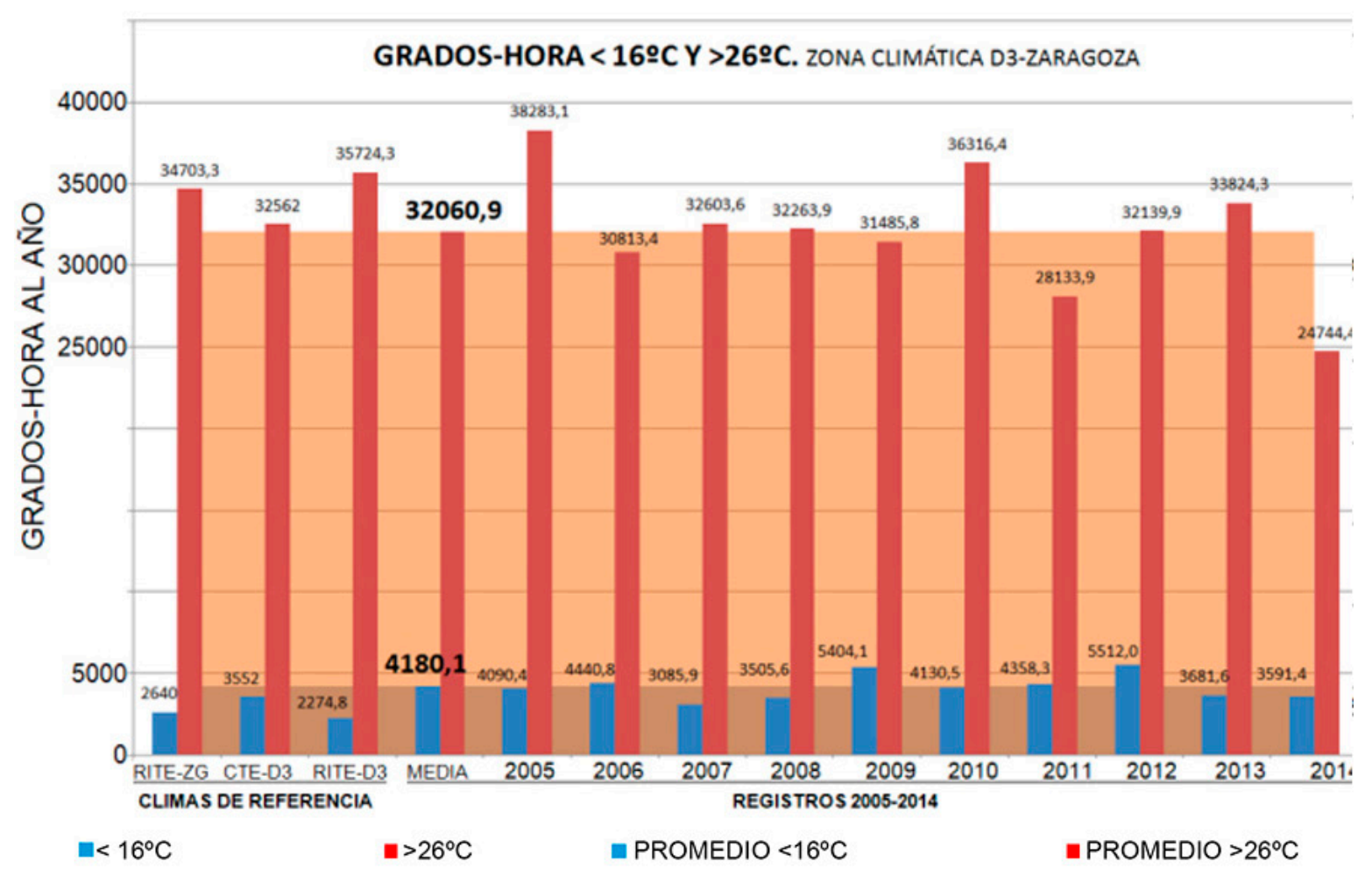




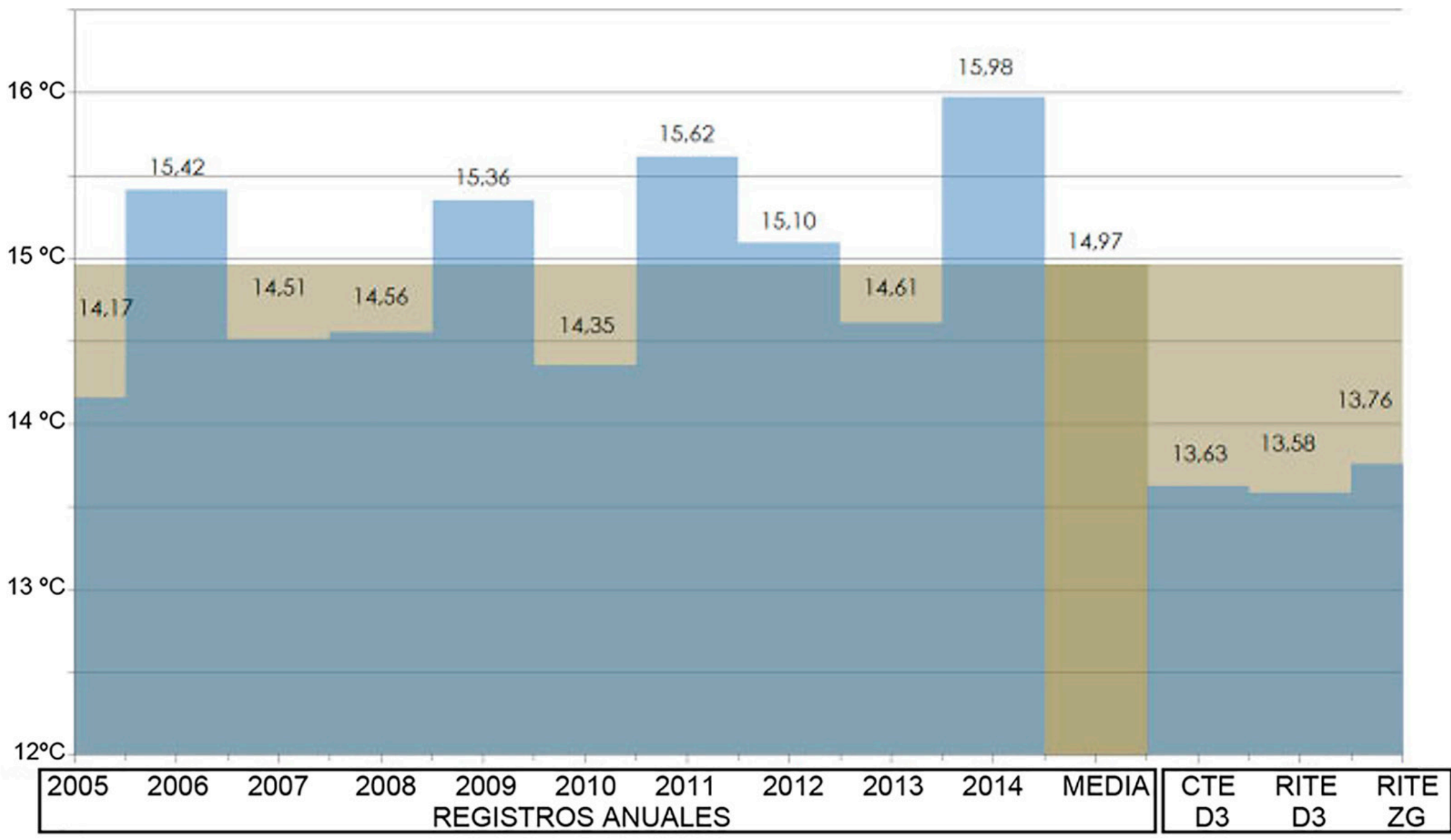

TEMPERATURAS MEDIAS ANUALES
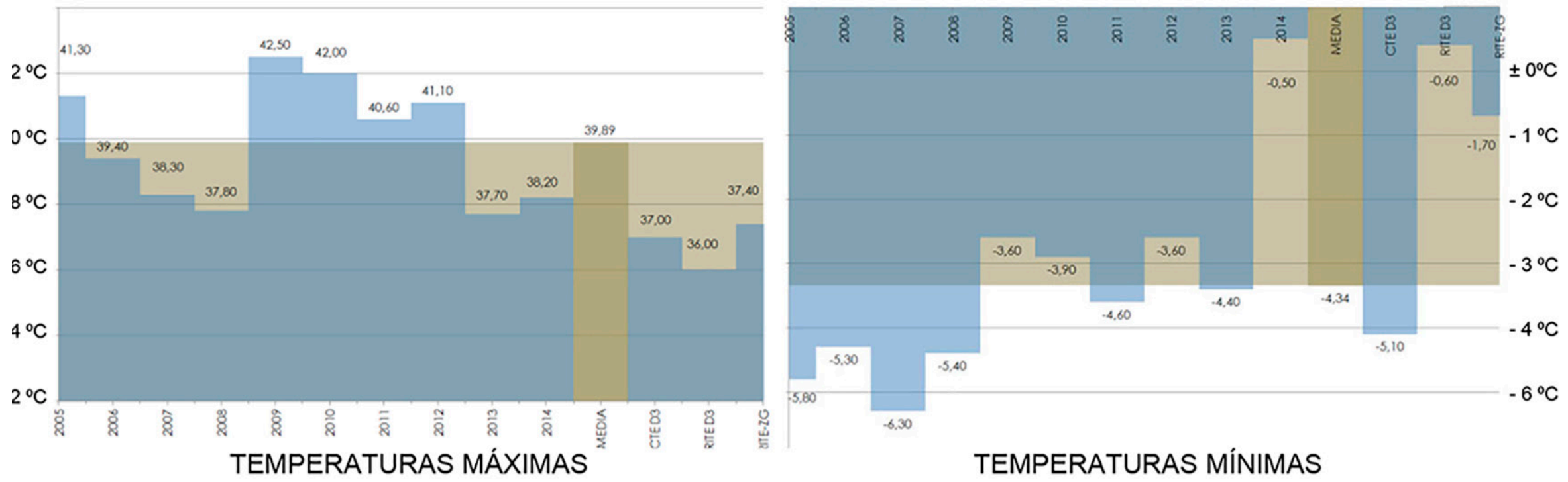

Figura 6. Tablas de las temperaturas comparadas mediana y mínima y máxima absoluta en varios climas de referencia como el asignado a Zaragoza por el RITE (RITE ZG) y los asignados para la zona por el Código Técnico de la Edificación (CTE D3) y por el RITE (RITE D3) y los valores registrados en Zaragoza entre los años 2005 y 2014 y su promedio anual.

Fuente: Elaboración propia.
También es elocuente la comparación entre los valores máximos y mínimos absolutos y la mediana y la demanda en grados-hora de climatización con diferentes temperaturas de consigna (Figura 7) o las diferencias en función de los periodos de recurrencia empleados para determinar estos valores (Tabla 1). 
DIFERENCIA NECESIDAD DE ENFRIAMIENTO $\left({ }^{\circ} \mathrm{C} / \mathrm{h}\right)$ EN \% CON EL CLIMA D3-CTE

D3-RITE

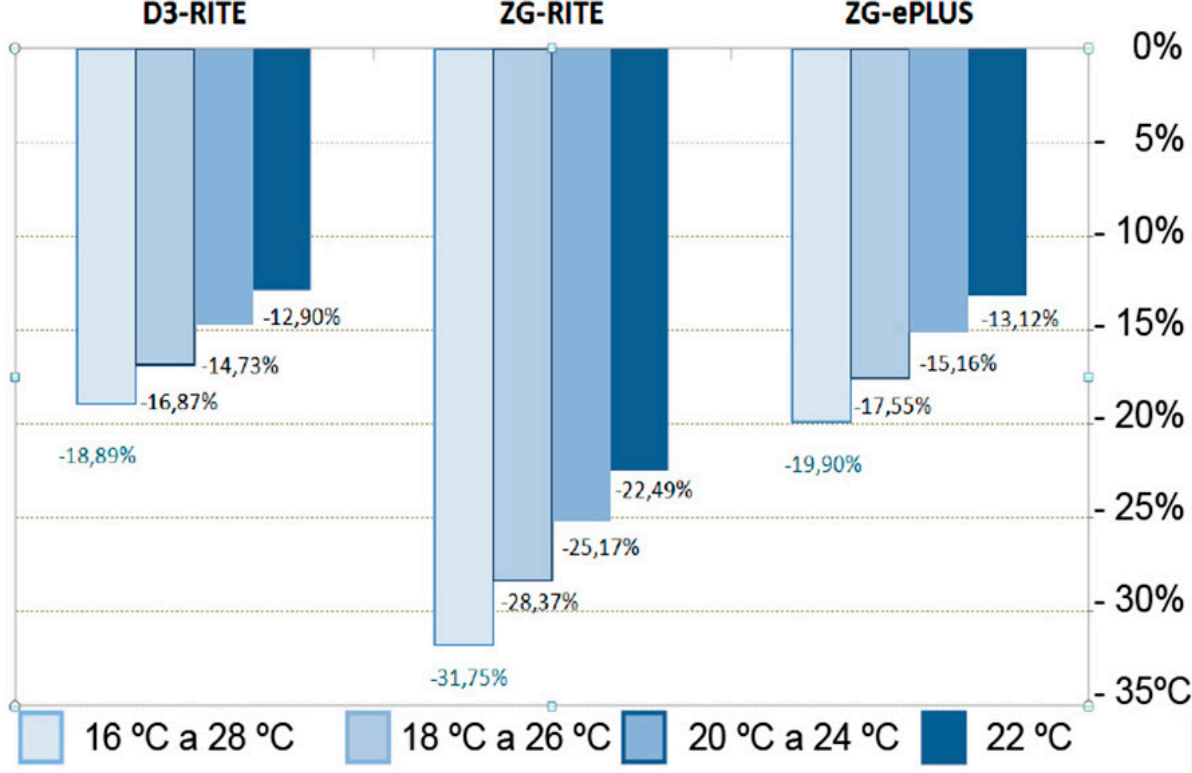

DIFERENCIA DE NECESIDAD DE CALEFACCIÓN $\left({ }^{\circ} \mathrm{C} / \mathrm{h}\right)$ EN \% CON EL CLIMA D3-CTE

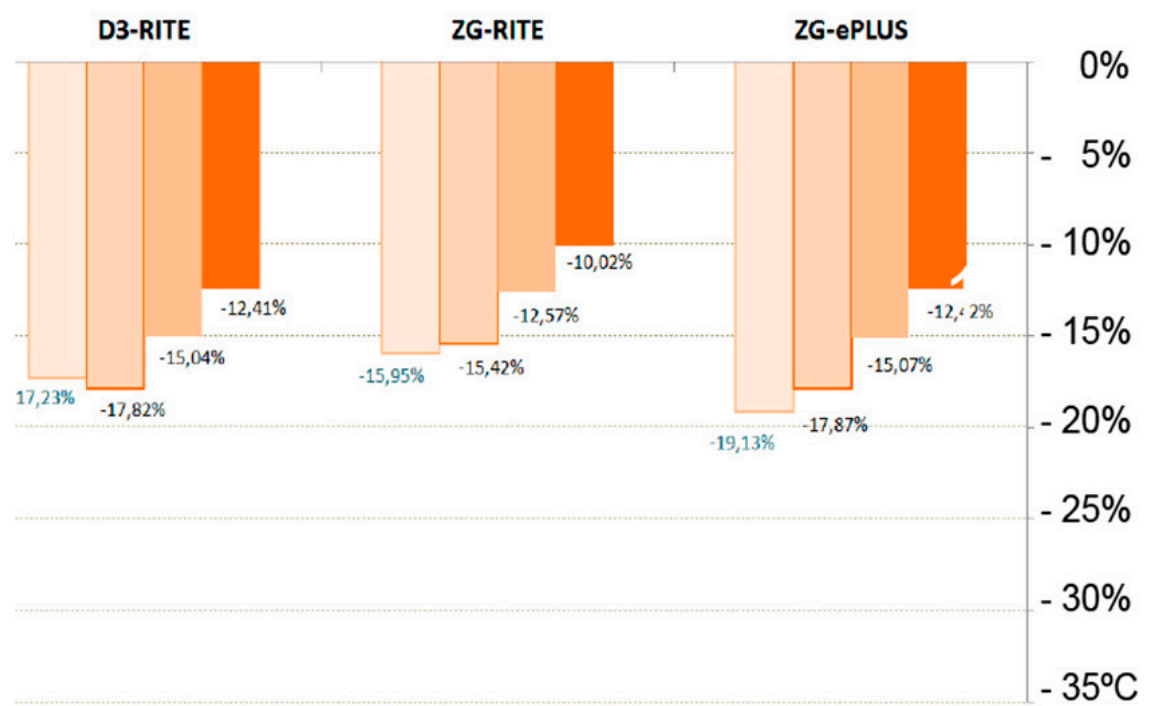

\begin{tabular}{l|l|l|l|l|l}
$16^{\circ} \mathrm{C}$ a $28^{\circ} \mathrm{C}$ & $18^{\circ} \mathrm{C}$ a $26^{\circ} \mathrm{C}$ & $20^{\circ} \mathrm{C}$ a $24^{\circ} \mathrm{C}$ & $22^{\circ} \mathrm{C}$
\end{tabular}
Figura 7. Tabla comparada con la diferencia de grados-hora de calefacción y refrigeración que es necesario climatizar si se considera necesaria la climatización con una temperatura de consigna $22^{\circ} \mathrm{C}$, o si se considera confortable un rango de temperaturas exteriores entre $20^{\circ} \mathrm{C}-24^{\circ} \mathrm{C}, 18^{\circ} \mathrm{C}$ $26^{\circ} \mathrm{C}, 16^{\circ} \mathrm{C}-28^{\circ} \mathrm{C}$ en los climas asignados a la ciudad de Zaragoza. Se incluyen los asignados por el RITE a la zona (D3-RITE), por el RITE a la ciudad (ZG-RITE D3) y por el procedimiento informático más divulgado (ZG-ePLUS).

Fuente: Elaboración propia.

Tabla 1. Tabla comparada de los porcentajes de variación de las oscilaciones térmicas y los valores medios para periodos de recurrencia de un año (2014), 3 años (2012-2014), cinco años (20102014) y diez años (2005-2014) según los valores registrados en AEMET.

Fuente: Elaboración propia.
Tabla 2. Caracterización de varias estancias de una vivienda unifamiliar aislada en Guadarrama. Madrid. (España).

Fuente: Elaboración propia.

\begin{tabular}{|c|c|c|c|c|c|c|c|c|}
\hline & \multicolumn{6}{|c|}{ OSCILACIÓN (ํC) } & \multicolumn{2}{|r|}{ MEDIA } \\
\hline & \multicolumn{2}{|c|}{ MÁXIMA } & \multicolumn{2}{|c|}{ MEDIA } & \multicolumn{2}{|c|}{ MÍNIMA } & \multirow[b]{2}{*}{$\stackrel{\circ}{ } \mathrm{C}$} & \multirow{2}{*}{$\begin{array}{c}\text { REDUCCIÓN } \\
\%\end{array}$} \\
\hline & อC & $\%$ & $\stackrel{\circ}{ } \mathrm{C}$ & $\%$ & $\stackrel{\circ}{ } \mathrm{C}$ & $\%$ & & \\
\hline ANUAL & 2,20 & $93 \%$ & 2,10 & $89 \%$ & 2,80 & $118 \%$ & 2,37 & \\
\hline MEDIA - 3 AÑOS & 1,67 & $90 \%$ & 1,68 & $91 \%$ & 2,18 & $118 \%$ & 1,84 & $22 \%$ \\
\hline MEDIA - 5 AÑOS & 1,15 & $76 \%$ & 1,47 & $97 \%$ & 1,93 & $128 \%$ & 1,52 & $36 \%$ \\
\hline MEDIA - 10 AÑOS & 0,77 & $62 \%$ & 1,19 & $83 \%$ & 1,79 & $143 \%$ & 1,25 & $47 \%$ \\
\hline
\end{tabular}

Los valores meteorológicos se obtienen en localizaciones donde la influencia de los obstáculos es mínima, mientras que el edificio se enfrenta a las condiciones que el mismo provoca y que serán diferentes dependiendo de su orientación, su exposición y su forma. Esta influencia configura el microclima de proximidad, que recoge los valores climáticos considerando la influencia del edificio y su entorno. Puede comprobarse su relevancia comparando las temperaturas registradas en una estación meteorológica de referencia con las determinadas junto al edificio en distintas orientaciones, observando su influencia en las temperaturas interiores.

La naturaleza de la edificación y su capacidad de adoptar diversas estrategias de adaptación al clima es de vital importancia para la aclimatación interior. Como ejemplo, puede considerarse la evolución diaria de la temperatura y la humedad en cuatro estancias de una misma vivienda unifamiliar aislada, situada en un clima continental mediterráneo a 1000 metros de altitud, con una categoría climática $\mathrm{E}$, siendo la más severa de las existentes en la legislación española (CTE). Estas estancias se caracterizan por diferentes valores de inercía térmica, aislamiento térmico, exposición solar y volumen de aire interior según se indica en la Tabla 2.

\begin{tabular}{|c|c|c|c|c|}
\hline ESTANCIA & $\begin{array}{c}\text { INERCIA } \\
\text { TÉRMICA }\end{array}$ & $\begin{array}{c}\text { AISLAMIENTO } \\
\text { TÉRMICO }\end{array}$ & $\begin{array}{c}\text { EXPOSICIÓN } \\
\text { SOLAR }\end{array}$ & $\begin{array}{c}\text { VOLUMEN AIRE } \\
\text { INTERIOR }\end{array}$ \\
\hline E1 & ALTA & BAJO & MEDIA & ALTO \\
\hline E2 & MEDIA & MEDIO & ALTO & BAJO \\
\hline E3 & MEDIA & MEDIO & BAJO & BAJO \\
\hline E4 & BAJA & ALTO & ALTA & ALTO \\
\hline
\end{tabular}

La temperatura interior en estancias con mucha inercia térmica (1) se mantiene casi constante y muy próxima a los $18^{\circ} \mathrm{C}$, lo que obligaría a incrementar el arropamiento de 1 clo a 2 o 2,5 clo. Las estancias soleadas, aisladas y de inercia moderada (2 y 4) requieren un mayor arropamiento nocturno y evacuar calor por ventilación durante el día, ya que pueden alcanzar temperaturas muy por encima de las de confort. En un día nublado, la falta de radiación reduce considerablemente la temperatura y con ella los periodos confortables haciendo necesario incrementar el arropamiento y aportar calor para alcanzar condiciones de uso apropiadas, especialmente cuando la inercia es menor (4) (Figura 8). 


\section{PERIODO TEMPLADO DÍA SOLEADO. GUADARRAMA. MADRID (ESPAÑA)}

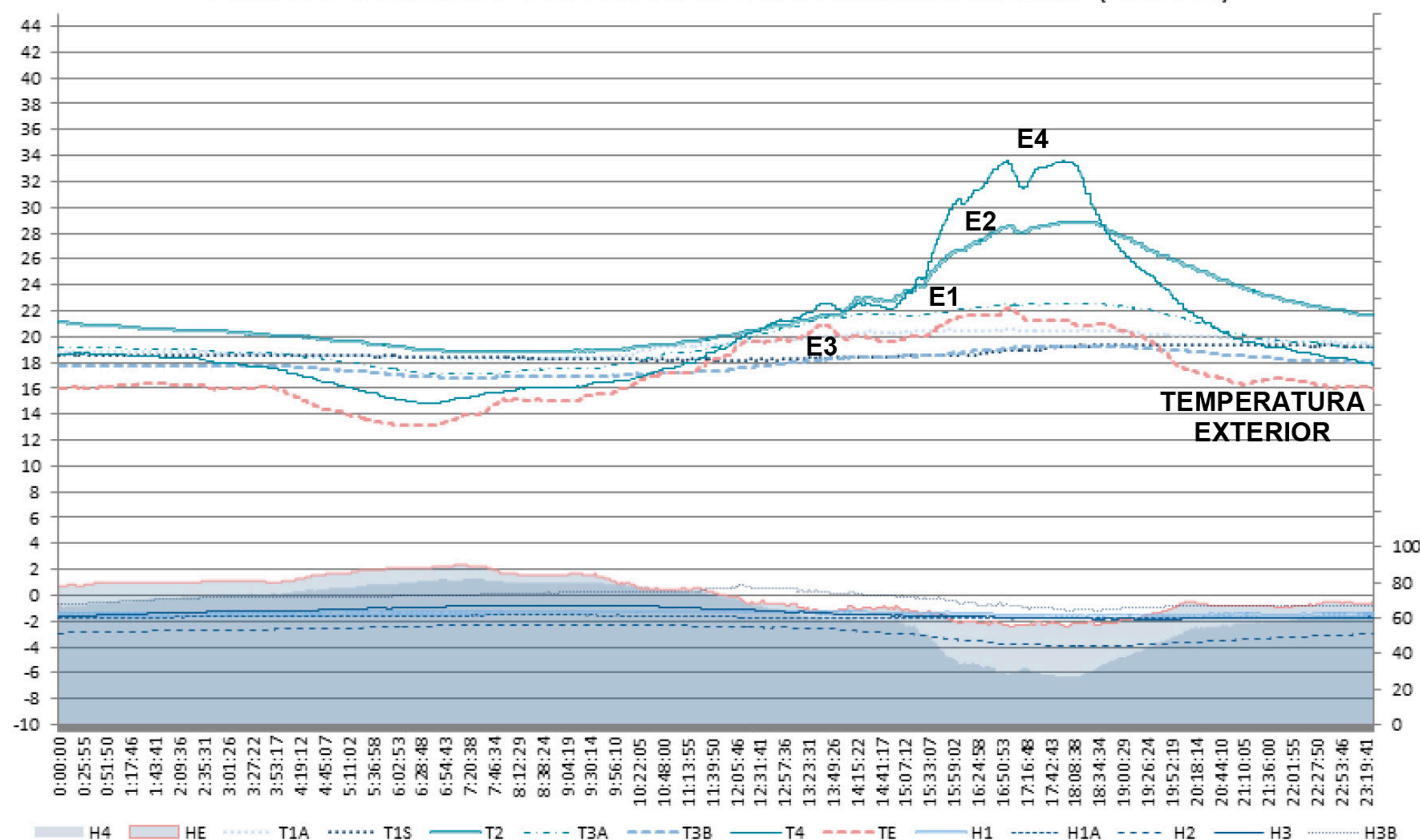

PERIODO TEMPLADO DÍA NUBLADO TRAS VARIOS DÍAS SOLEADOS. GUADARRAMA. MADRID (ESPAÑA)

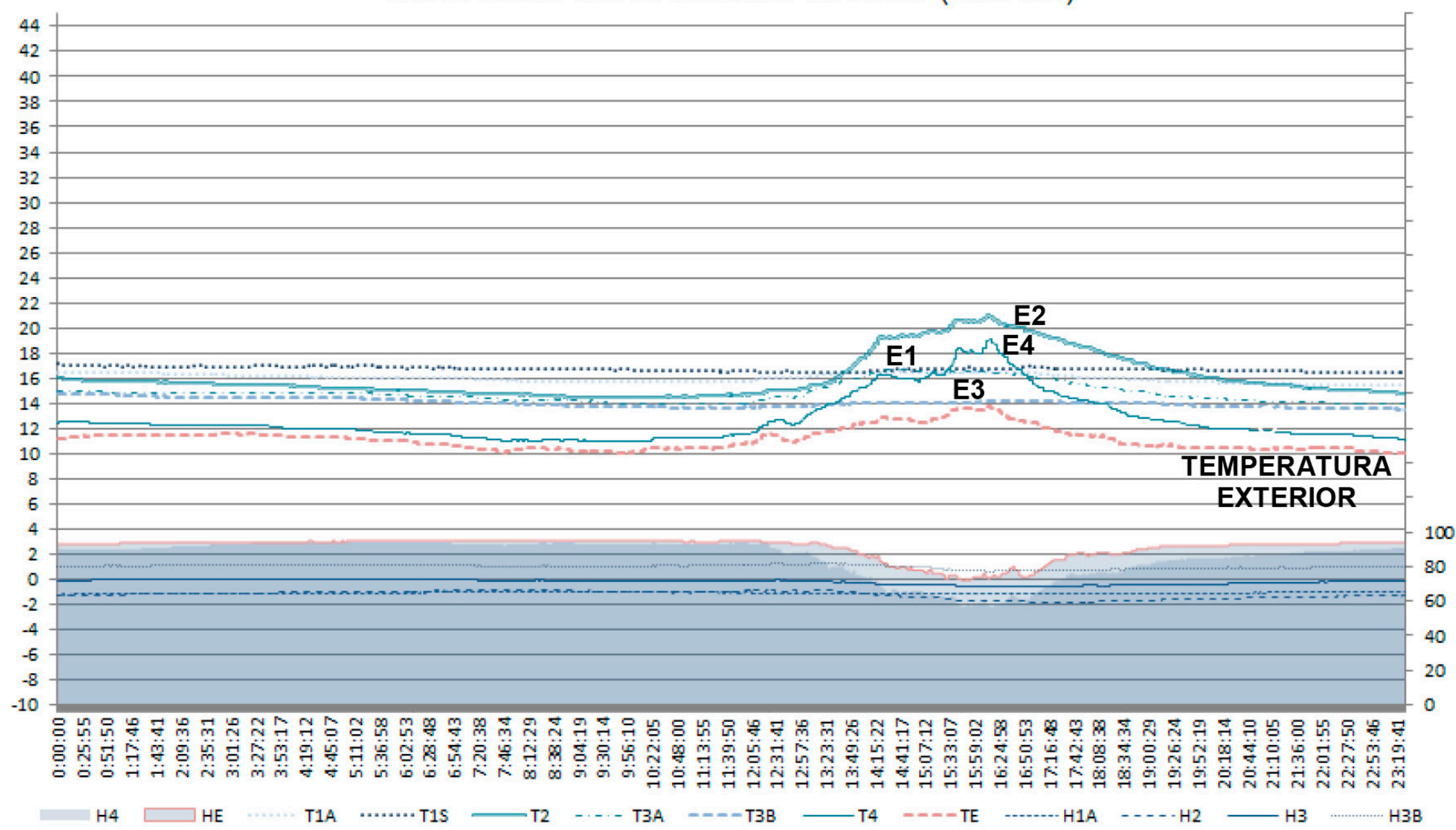

Figura 8. Evolución de la temperatura y la humedad el día 3/03 (superior) y el 12/03 (inferior) en una vivienda unifamiliar aislada en Guadarrama. Madrid (España).

Fuente: Elaboración propia

An el centro urbano de Zaragoza, la influencia de un edificio en las temperaturas de su entorno próximo, en el patio de luces interior y en la calle, se observan al compararlas con las registradas en las tres estaciones meteorológicas de referencia más próximas. Lo anterior también tiene reflejo en las temperaturas registradas en el interior del edificio, como se observa comparando las temperaturas en una estación de la Agencia Española de Meteorología (CANL), en una estación meteorológica situada sobre el edificio (MET SP), en un patio de luces interior al edificio $\left(3^{\circ} \mathrm{F} \mathrm{PL}\right)$, en un patio de manzana ( $\left.3^{\circ} \mathrm{F}-\mathrm{P}\right)$ y en el interior de la vivienda en una habitación con fachada al patio interior ( $\left.3^{\circ} \mathrm{F}-\mathrm{D}\right)$ y con fachada al patio de manzana ( $\left.3^{\circ} \mathrm{F}-\mathrm{S}\right)$ (Figura 9 ). 


\section{ZARAGOZA_CENTRO URBANO_15 al 20_11_2014}

EVOLUCIÓN DE LA TEMPERATURA BAJANDO Y SUBIENDO DESDE LA ZONA DE CONFORT

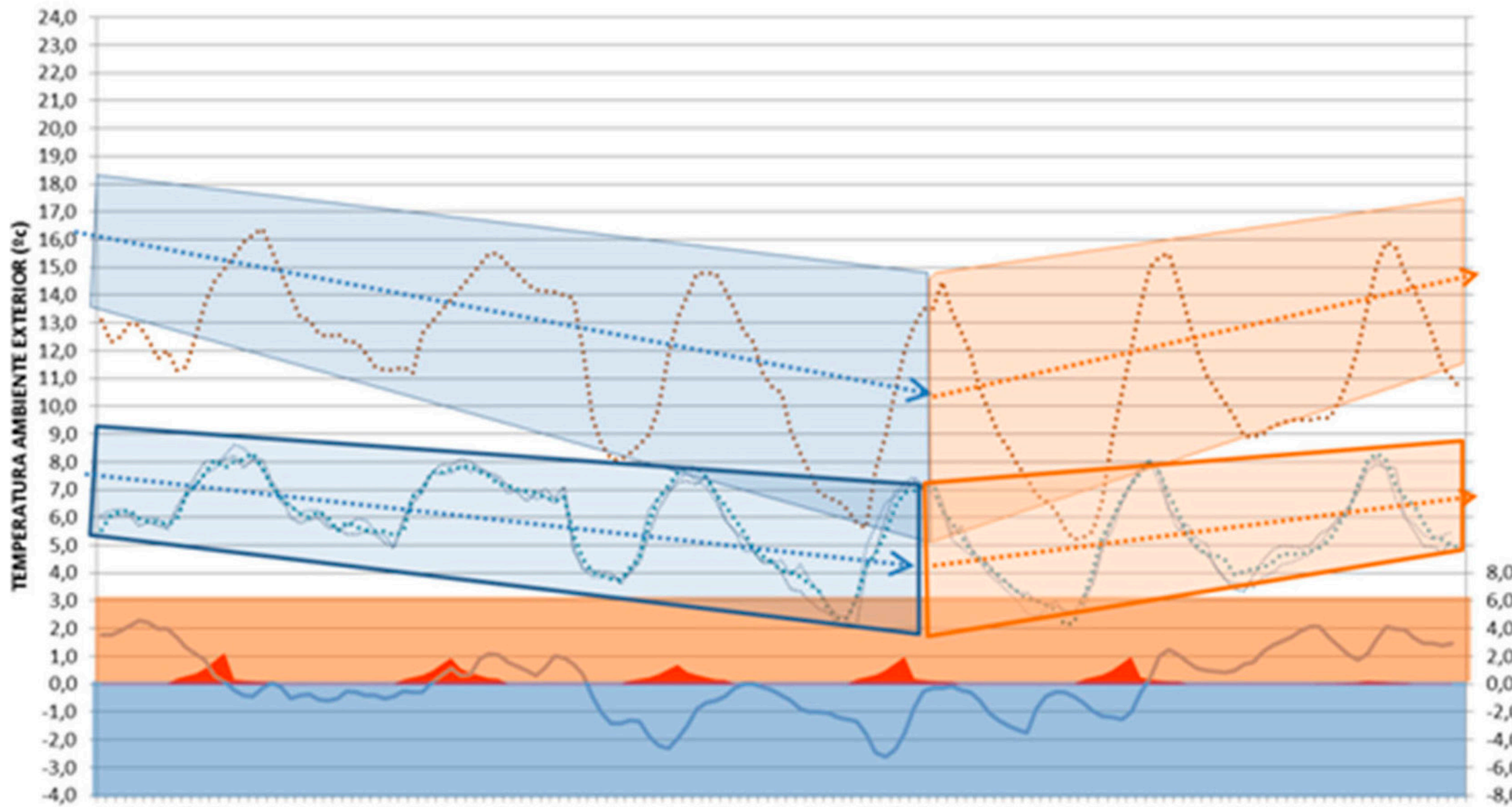

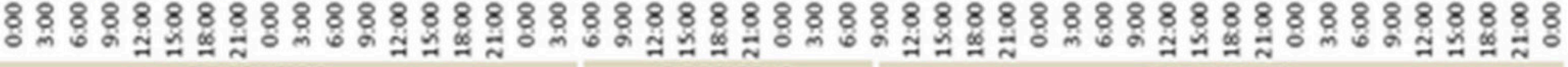
UÉ ZRQueroo INSOLACIÓN EST_SP $1^{\circ}$ PL-CALLE VALD

AER CNAL

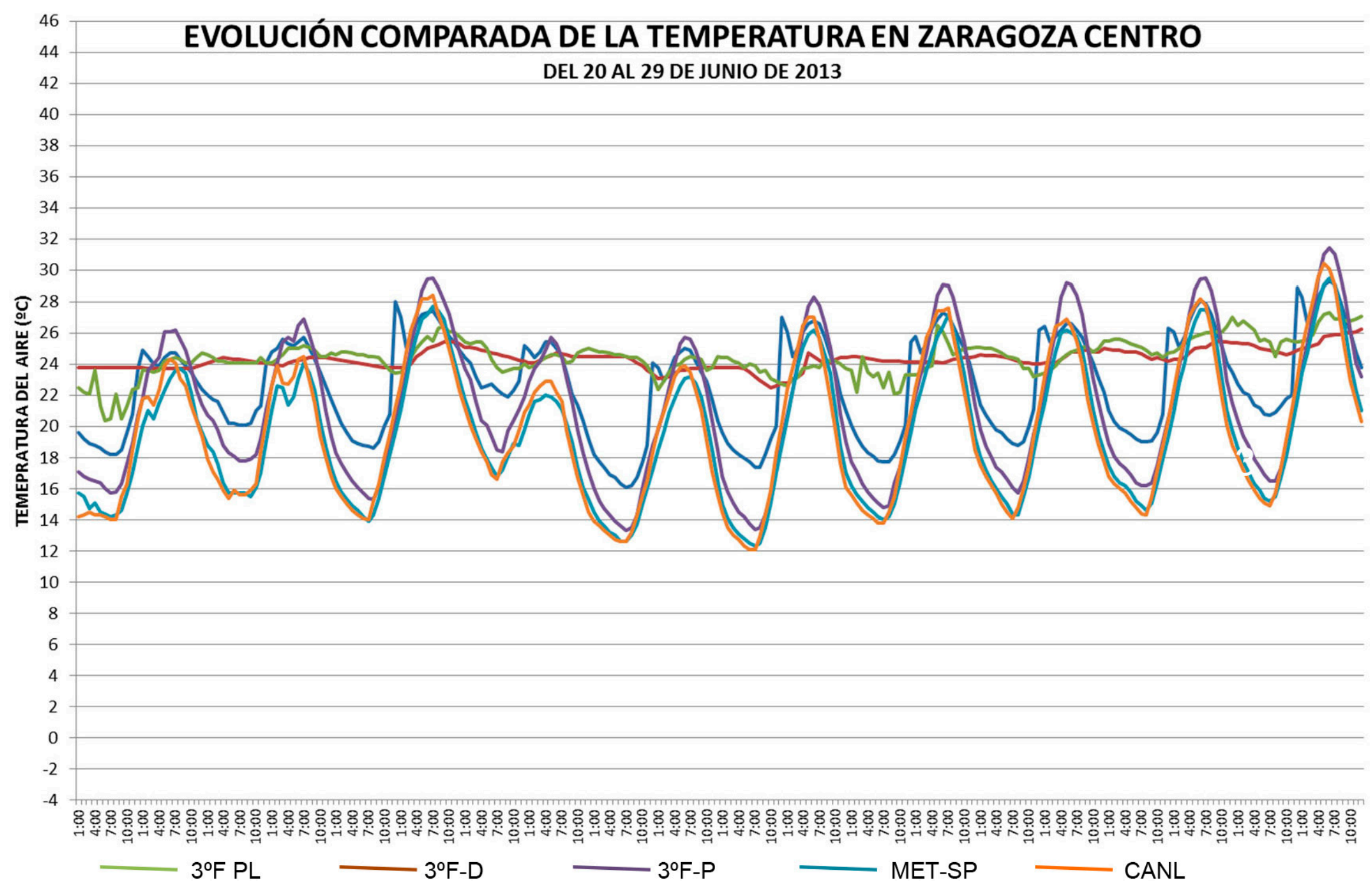

Figura 9. Gráfica comparada de la temperatura registrada en el centro urbano de Zaragoza entre el 15 y el 20 de noviembre de 2013 en distintas localizaciones de un edificio en bloque (arriba). Se recogen los datos procedentes de tres estaciones meteorológicas de referencia (VALD, AER y CANL), la estación meteorológica situada en el edificio (MET_SP) y, abajo y en el eje derecho, la diferencia entre las temperaturas registradas en el patio de luces interior y la calle a la altura de la $1^{\mathrm{a}}$ planta (PL-CALLE). Evolución horaria de las temperaturas en el centro urbano de Zaragoza entre el 20 y el 29 de junio de 2013 en distintas localizaciones de un edificio en bloque (abajo). Se recogen los datos procedentes de la estación meteorológica de referencia (CANL), la estación meteorológica situada en el edificio (MET_SP) y a la altura de la $3^{\mathrm{a}}$ planta. En un patio de luces interior ( $\left.3^{\circ} \mathrm{F} \mathrm{PL}\right)$, en el patio de manzana $\left(3^{\circ} \mathrm{F}-\mathrm{P}\right)$, en una estancia contigua al patio de luces $\left(3^{\circ} \mathrm{F}-\mathrm{D}\right)$ y contigua al patio de manzana $\left(3^{\circ} \mathrm{F}-\mathrm{S}\right)$

Fuente: Elaboración propia. 
La comprobación en anualidades completas puede ser adecuada para estimar el consumo de los sistemas de climatización y los patrones de consigna más apropiados, pero las estrategias bioclimáticas se aplican simultánea o alternativamente cuando se dan las condiciones apropiadas durante la vida del edificio, por lo que su entrada en servicio es muchas veces intermitente y con combinaciones muy variadas. Observar la respuesta diaria exige la confección de días tipo de cada periodo homogéneo, pudiéndose testar este comportamiento para cada una de las franjas de homogeneidad térmica obtenidas de las secuencias térmicas disponibles, independientemente de su amplitud en el periodo analizado, y extrapolar sus valores a su recurrencia determinada (Figura 10).

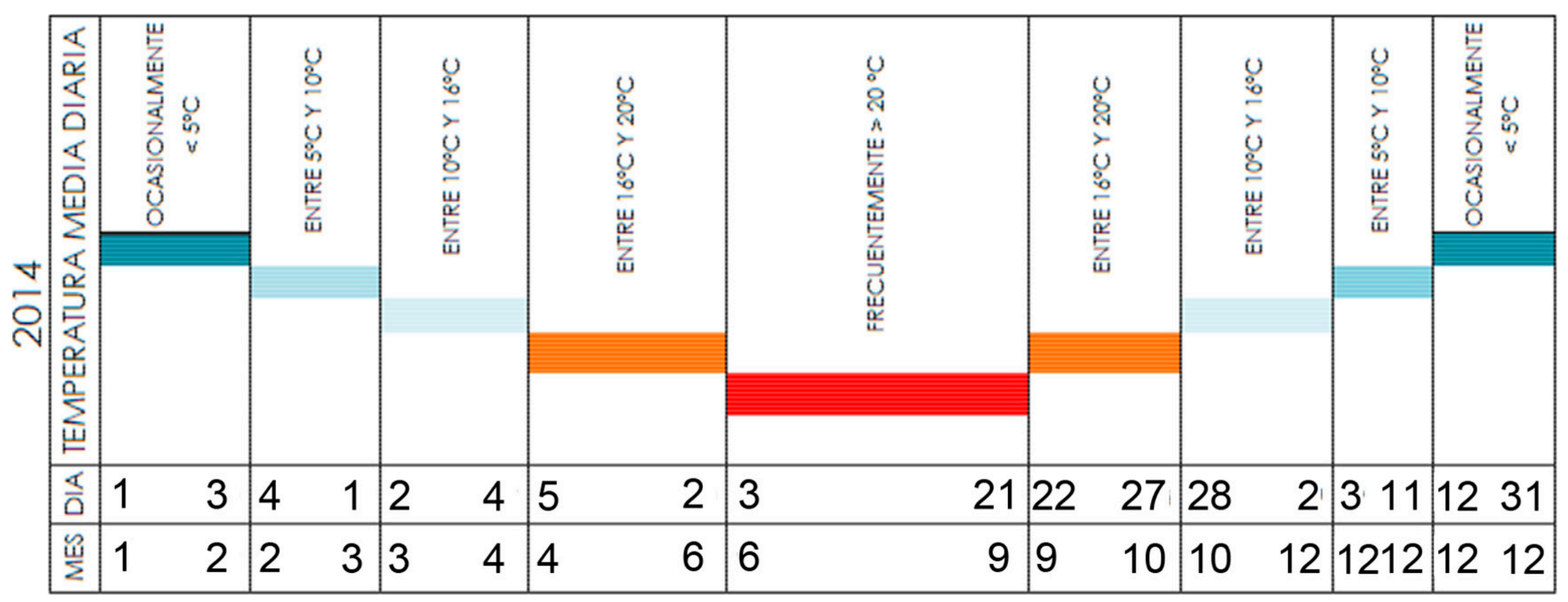

Figura 10. Estimación de la aplicación de las franjas de homogeneidad térmica al año 2014 para el centro de Zaragoza, España.

Fuente: Elaboración propia.

\section{Condiciones de confort y de consigna}

Las condiciones de confort son determinantes para conocer las estrategias bioclimáticas a emplear y los equipos y consumos precisos para acondicionar los edificios. Para no cometer errores en el diseño, la prescripción y la estimación de consumos, debe considerarse que el confort es una variable que depende de muchos factores. Una primera consideración se refiere a la estacionalidad del arropamiento. Aunque actualmente se considera un arropamiento de 0,5 clo en verano y 1 clo en invierno, existen situaciones en las que pueden darse valores diferentes, especialmente en poblaciones vulnerables. Las condiciones óptimas para los que están habituados a un clima varían con respecto a los que no lo están y, lo que es aún más importante, si se aplica a alojamientos de colectivos diferentes la tolerancia será también diferente.

Los valores normalizados de confort se deben confrontar con los percibidos por los usuarios de los edificios. Los esfuerzos en este sentido deben replicarse para poblaciones con diferente nivel económico y características, como pueden ser niños, mujeres embarazadas 0 ancianos, y para diferentes actividades. Al aplicar estos criterios a un edificio con viviendas sociales en el centro urbano de Zaragoza, se puede comprobar la diferencia entre las temperaturas consideradas confortables en función de distintos criterios y su relación con las temperaturas reales registradas en el exterior (Figura 11). De todos ellos se considera que, en este caso, la aplicación de los valores indicados por el confort adaptativo comporta una mejor estimación del consumo, según se comprueba por ejemplo para Madrid (Godoy, 2012), o para Holanda o Chequia (Centnerova \& Hensen, 2001). Constatándose que las reducciones de consumo son mayores cuanto más bajas son las temperaturas (Godoy, 2012).

Caracterización bioclimática de edificios, materiales y sistemas constructivos

Las prestaciones que se exigen a los materiales, sistemas constructivos y, en definitiva, a los edificios están reguladas en los códigos y normas nacionales en España en el Código Técnico de la Edificación (CTE). Estos hacen referencia a aspectos de seguridad estructural, como la resistencia o la estabilidad, de seguridad frente a los riesgos, como la protección contra incendios o frente a los sismos, o de habitabilidad, como puede 


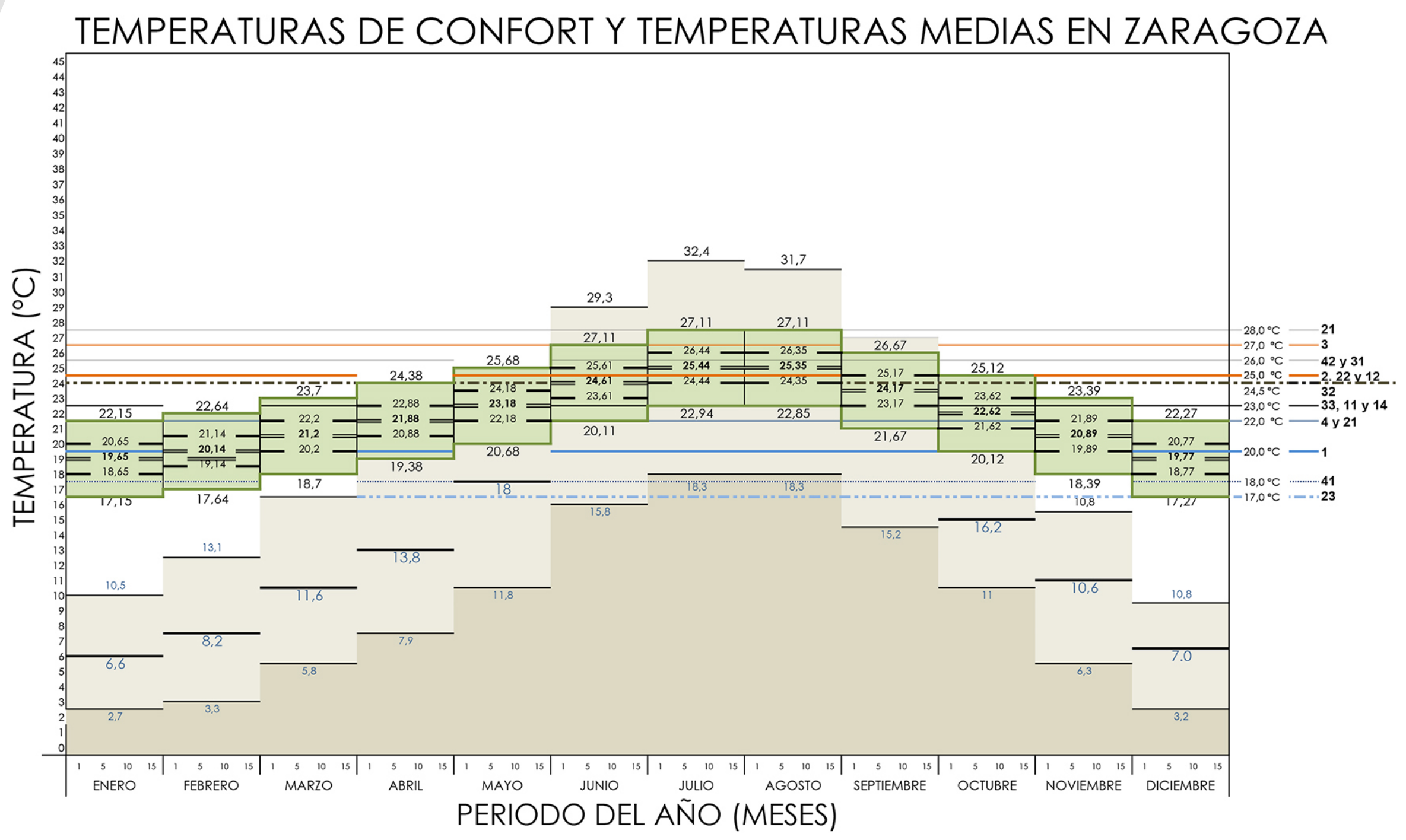

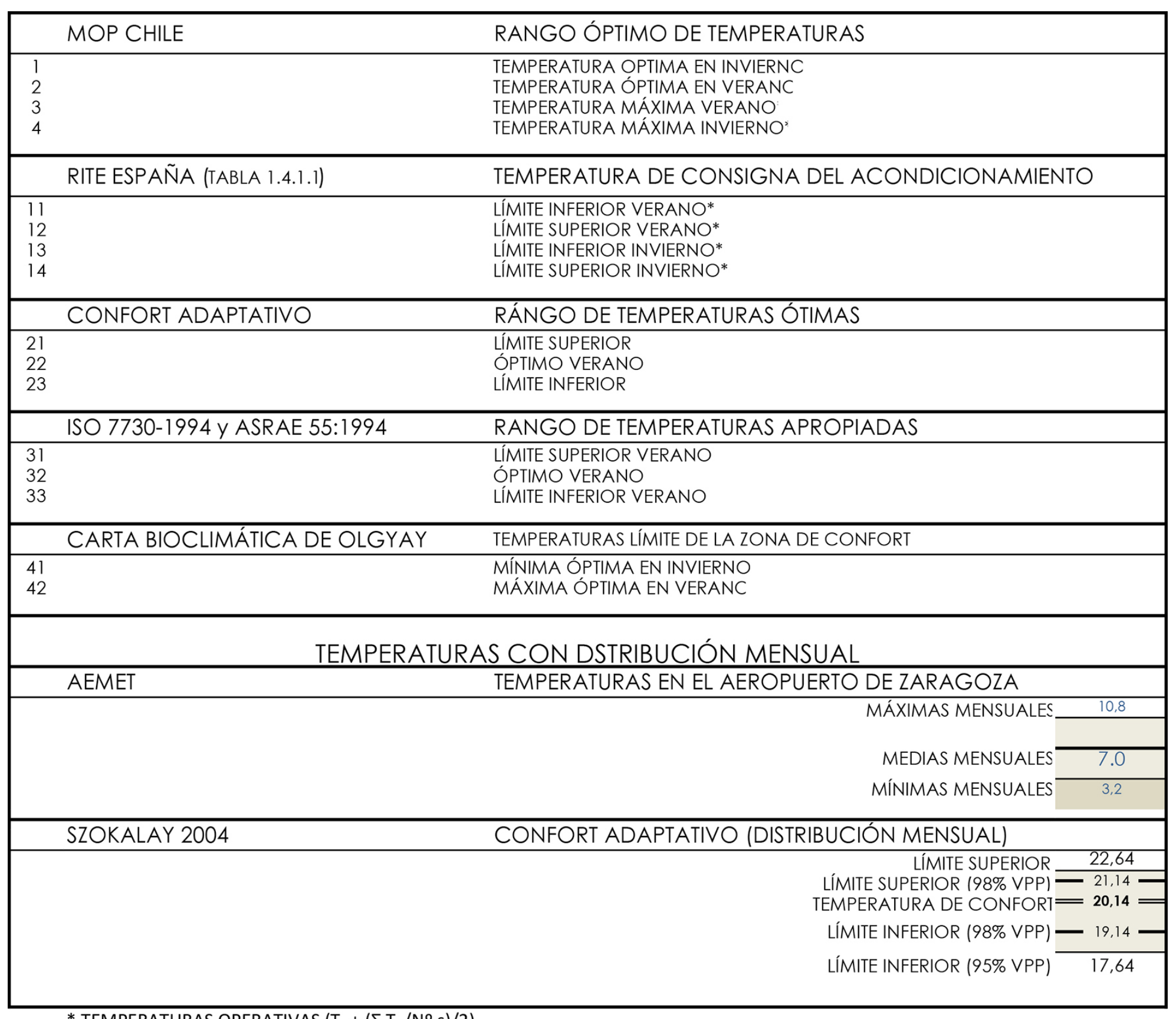

${ }^{*}$ TEMPERATURAS OPERATIVAS $\left(\mathrm{T}_{\mathrm{a}}+\left(\Sigma \mathrm{T}_{\mathrm{s}} / \mathrm{N} \mathrm{N} s\right) / 2\right)$

Figura 11. Relación entre los valores medios mensuales de las temperaturas registradas en la estación meteorológica de AEMET en el aeropuerto de Zaragoza, las temperaturas de confort adaptativo propuestas por Szocalay (2004) y otras temperaturas de confort propuestas por diversos autores y regulaciones. 
ser la impermeabilidad, el aislamiento acústico, la salubridad o la eficiencia energética. Estas prestaciones están en parte acreditadas por el Marcado CE que se exige a los productos autorizados para su empleo en Europa. Complementariamente, es necesario acreditar las prestaciones que son exigidas específicamente para cada caso por la legislación vigente. Esta acreditación documental es una parte fundamental de la memoria final de los proyectos de ejecución.

Las cualidades que se utilizan para el análisis bioclimático no están incluidas en la documentación estándar, por lo que es preciso desarrollar y extender bases de datos o catálogos, incluyéndolas para facilitar el trabajo de prescripción. En este sentido, se puede considerar el modelo desarrollado en el proyecto LIFE10 ENV/ES/439, realizado por un consorcio de empresas y entidades públicas, entre ellas la Universidad Politécnica de Madrid. Como muestra se aporta una de las fichas que forman parte de este catálogo, en la que también se incluyen los apartados para valorar su viabilidad y su colaboración a un desarrollo sostenible (Figura 12).

\section{Diseño y desarrollo de prácticas y estrategias constructivas}

La aplicación del análisis bioclimático al diseño arquitectónico de Olgyay, Givoni o Mazria, solo es el precursor de otros muchos desarrollados para diferentes localizaciones y aportando diversos sesgos, como la consideración de la energía embebida, la contaminación del aire interior o la contaminación electromagnética. Estos desarrollos se agrupan en catálogos de buenas prácticas, como el consolidado en Europa en 1999 con el sugerente título del Vitrubio Verde (Lewis \& Brophy, 2011) y otros más recientes (Roaf, 2010; Johnston \& Gibson, 2011; Wooley et al., 1997). Estas recomendaciones 0 estrategias se han divulgado en tablas o cuadros bioclimáticos de amplia difusión (Olgyay, 1998; Givoni, 1969; Mazria, 1979).

Otros muchos autores han desarrollado aplicaciones de carácter más o menos local como por ejemplo The American Institute of Architects (AIA) para Estados Unidos (AIA, 1984) o ADENE para Portugal (Porto, 2013), en relación a usos específicos como pueden ser el de los centros escolares (Cuhna, 1988), para regiones con climas predominantemente fríos o cálidos (Sevilla, 2000; Hyde, 2000; Koenigsberger et al., 1977), o para estrategias específicas como la inercia térmica (García Arroyo, 1983; Neila, 2000a), la construcción enterrada (Neila, 2004), el soleamiento (Neila, 2000b) o genéricos (Bedoya \& Neila, 1986; Moita, 1988; Szokolay 2008; Yañez, 1982; 1988; 1976). En otras ocasiones, se ocupan del estudio de edificios y sus equipamientos ya sea en Estados Unidos (Steedmann, 1978) o en Europa (Lewis 1987 a 1989) (Szokolay, 1975; Lewis \& Goulding, 1966). La aplicación de estrategias bioclimáticas es eficiente cuando estas se combinan, ya sea mediante una aplicación simultánea o sucesiva. La decisión de establecer, previamente al diseño, las estrategias a emplear y la forma de hacerlo es fundamental para conseguir los objetivos pretendidos ya que algunas de ellas son complementarias y otras incompatibles. Los programas informáticos predictivos, para realizar evaluaciones que consideren estas estrategias, deben ser informados de la forma en la que se estima su aplicación para aportar valores correctos sobre su implantación. No tendría sentido, por ejemplo, incrementar simultáneamente la acumulación de calor en la masa térmica del edificio, establecer sistemas para incrementar su captación mediante el soleamiento y el empleo de invernaderos si hay sobrecalentamiento interior en las horas centrales del día, si no se tiene en cuenta la forma en la que se secuenciarían estas estrategias.

Esta definición de las estrategias bioclimáticas puede complementarse con otras de carácter socioeconómico o cultural. Por ejemplo, para facilitar su empleo en la rehabilitación de viviendas sociales en España se ha elaborado dentro del programa LIFE10 ENV/ES/439 un asistente a la toma de decisiones que incluye los aspectos sociales y económicos precisos para hacer viable su implantación. En este asistente se han establecido cinco niveles. En un primer nivel se define el procedimiento de participación y la caracterización social de los agentes que intervendrán en el proceso de rehabilitación. Después se evalúa la viabilidad para abordar esta acción y las precauciones a tener en cuenta y, en caso de no ser viable, las medidas a tomar para hacerla posible. Se instruye, en tercer lugar, la toma de datos precisa para su diseño 


\section{NEW $/$ OLD SOLUTIONS HOUSING}

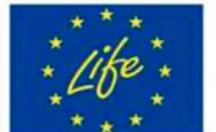

LIFE10 ENV/ES 439

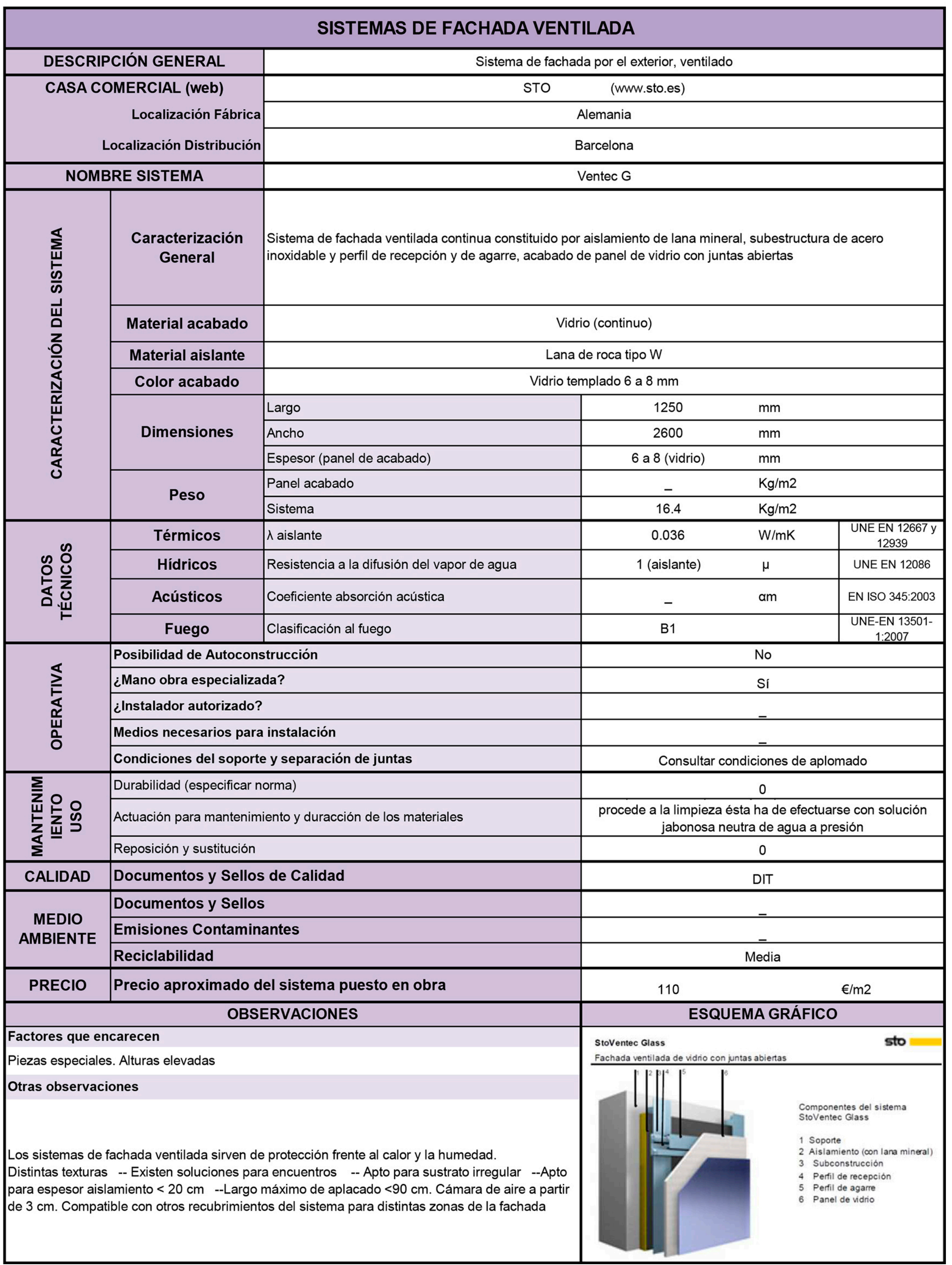


y comprobación de su desempeño una vez realizada. En una cuarta fase, se aportan las mejores técnicas disponibles y un conjunto de buenas prácticas para su diseño, ejecución y puesta en servicio. El proceso acaba con una estimación de las mejoras conseguidas con la rehabilitación (Figura 13).

\section{Métodos de comprobación "in situ" del desempeño bioclimático}

El registro de valores significativos es fundamental para comprobar las prestaciones de las estrategias bioclimáticas implantadas. El principal inconveniente en la toma de datos es realizarlo en condiciones de uso. La forma de realizar estos registros ha sufrido una gran transformación. Actualmente las soluciones inalámbricas permiten reducir las

\section{Herramienta N4O Apoyo Rehabilitación de Viviendas Sociales}

\section{NIVEL 5 ESTRATEGIAS}
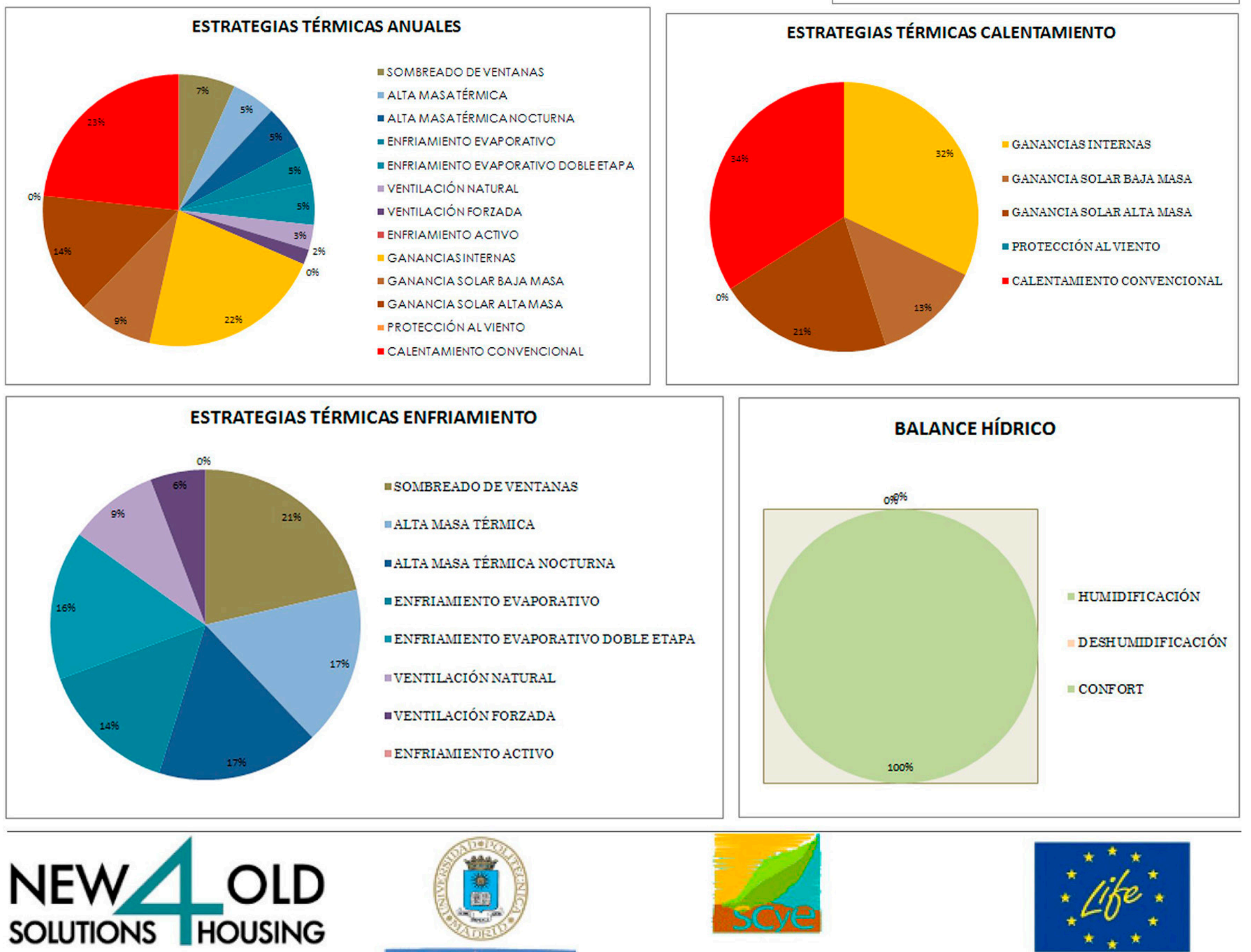

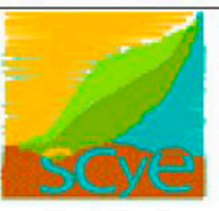

POLITÉCNICA

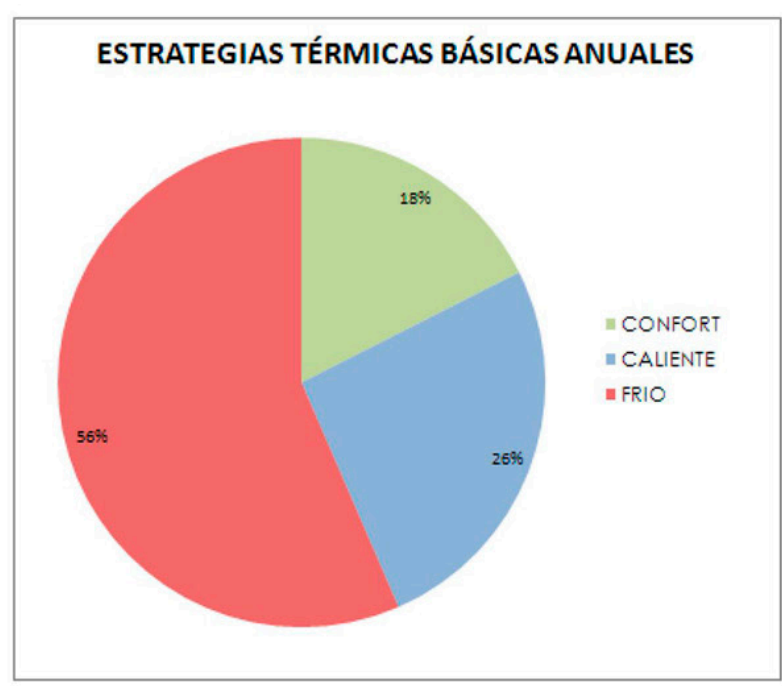

TRATEGIAS TÉRMICAS CALENTAMIENTO

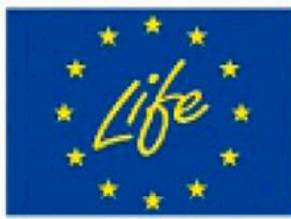

LIFE10 ENV/ES 439

Figura 13. Muestra de resultados de asistente de diseño para viviendas sociales. Fuente: Elaboración propia dentro del proyecto LIFE10 ENV/ES/439. 
Figura 14. Esquema del sistema de toma de datos, envío y registro diseñado para el proyecto LIFE e implantado en demostrador del centro histórico de Zaragoza.

Fuente: Elaboración propia en el LIFE 10 ENV/ ES/439.

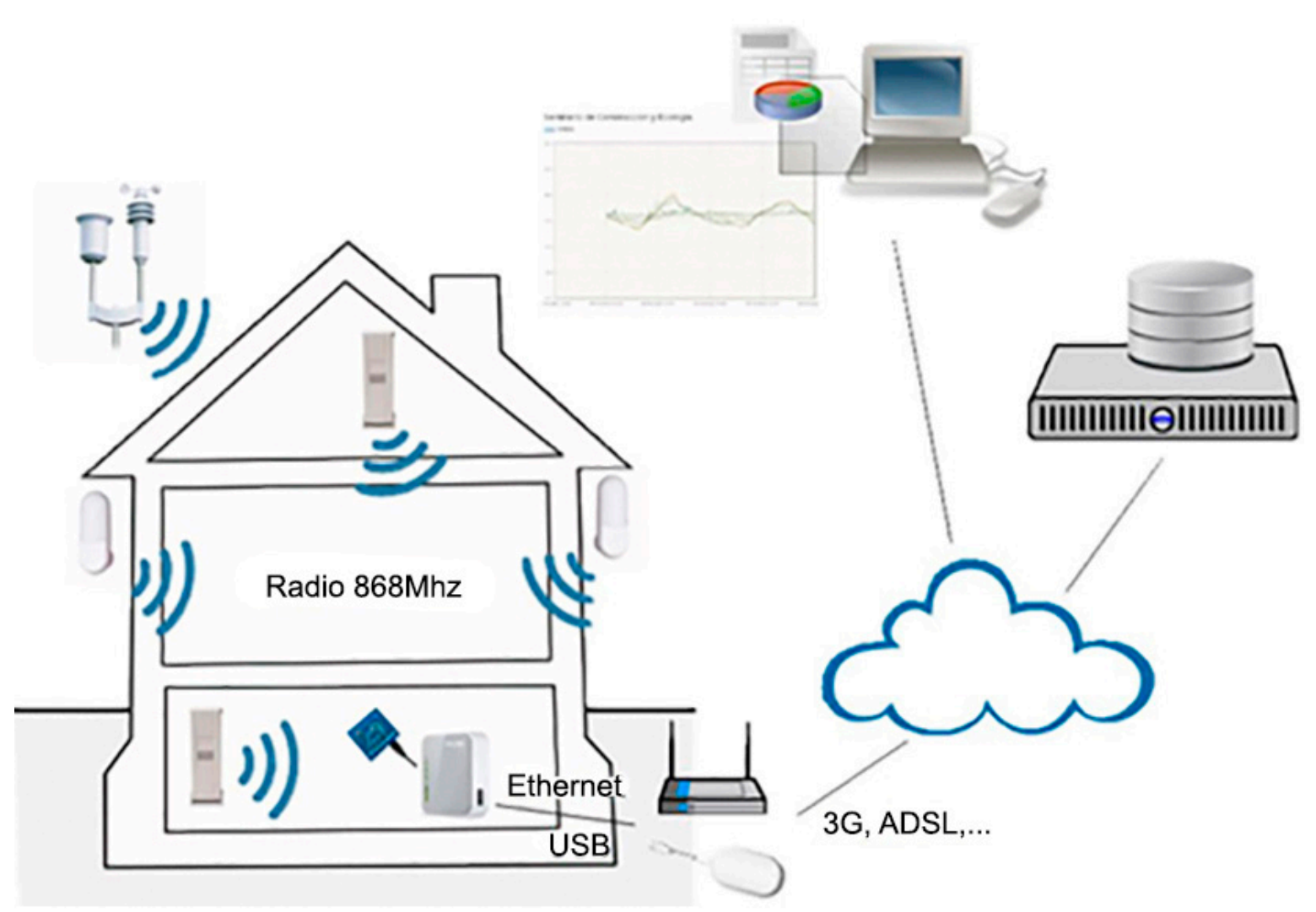

reticencias de los usuarios y facilitar la implantación de los sistemas de registro (Figura 14).

Estos datos son accesibles a través del servidor, donde se almacenan y permiten su consulta en línea y el acceso a los archivos de registros históricos ordenados por localización y fecha. Los datos registrados deben incluir las condiciones climáticas exteriores, las condiciones higrotérmicas y de confort interiores y las condiciones de uso. En este sentido, se ha mostrado especialmente significativa la calidad del aire interior. Actualmente la regulación en España considera la concentración de $\mathrm{CO} 2$ un buen indicador de la correcta renovación del aire en edificación. En los estudios realizados, se ha constatado que mantener la temperatura interior, evitando las infiltraciones y la ventilación exterior, conlleva altos niveles de concentración de contaminantes interiores. En esta toma de datos también deben tener cabida otros procedimientos más sofisticados que incluyan, por ejemplo, la toma de imágenes termográficas (Öhmann, 2014; Vollmer \& Möllmann, 2010; Rico, 2009), o forzar las condiciones ambientales para hacer más visible la respuesta del edificio, como ocurre con la extracción forzada del aire de las estancias para detectar las infiltraciones (Figura 15).

Validación de los procedimientos informáticos que acreditan la habitabilidad

La evaluación conjunta de la eficiencia y la habitabilidad se soporta frecuentemente en programas informáticos que replican la transferencia de energía y arrojan conclusiones que no se han comprobado sobre edificios construidos tal y como se han simulado y en unas condiciones de contorno similares a aquellas en las que los edificios están insertos. Estos procedimientos han demostrado alejarse mucho de la realidad, siendo ineficaces para garantizar que las condiciones de confort sean las apropiadas en un momento determinado. Esto no es relevante si los edificios disponen de sistemas mecánicos que modulan su actividad, ajustándola a las demandas reales en cada momento, independientemente de los valores estimados. Nuestra experiencia indica que solo validando previamente las simulaciones con la respuesta real de la edificación pueden obtenerse previsiones fiables. Consideramos que, para establecer las prioridades de diseño, es preferible la evaluación de las combinaciones de estrategias bioclimáticas en periodos cortos, ajustados a las franjas de homogeneidad térmica y estableciendo unas directrices de uso y accionamiento apropiadas a ellos.

\section{La regulación y el marco normativo}

La regulación y las normas de obligado cumplimiento son, en la Unión Europea, un sistema muy eficaz para la protección del usuario del edificio. La inclusión de 


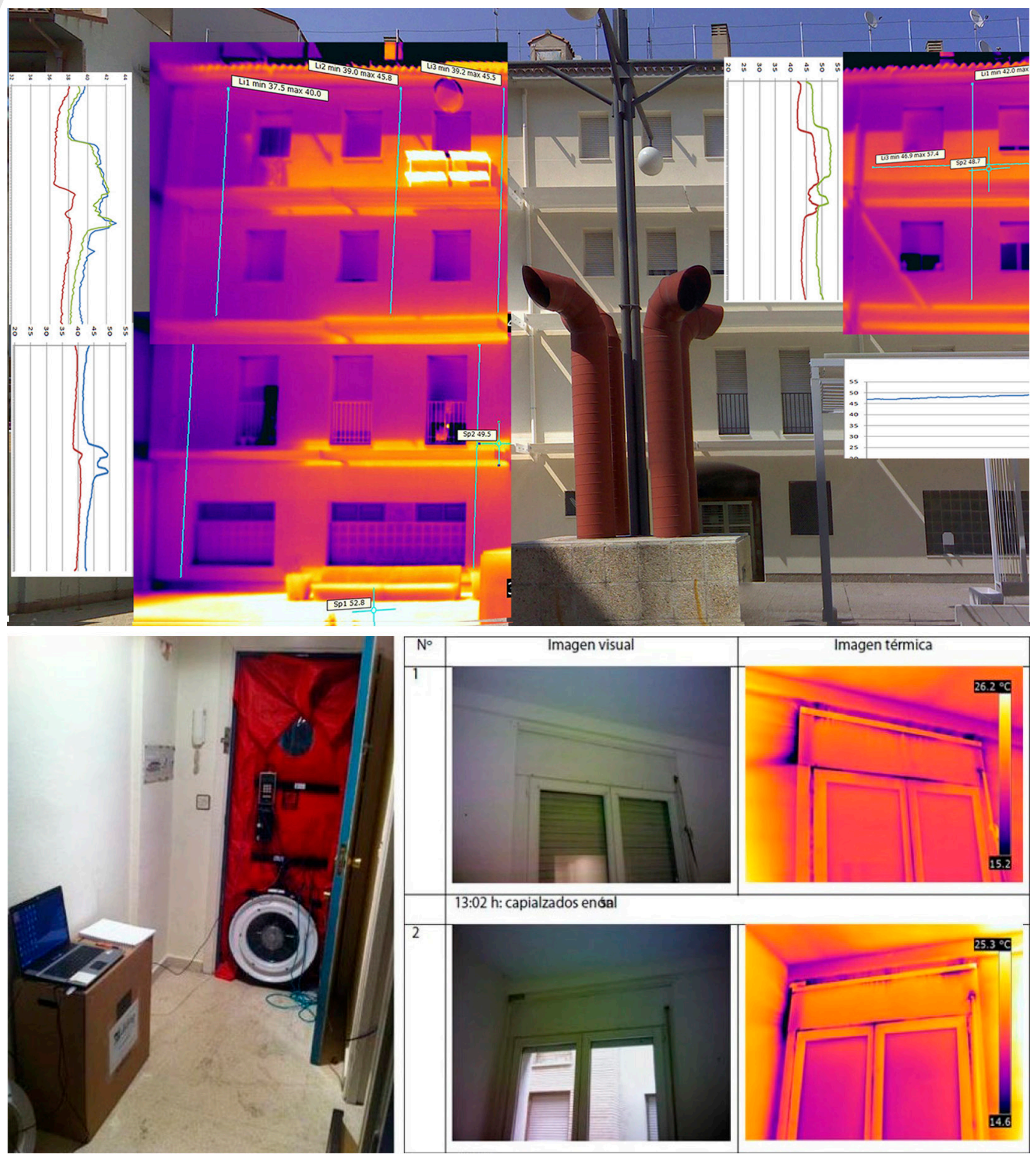

Figura 15. Ensayo mediante termografía infrarroja de la temperatura alcanzada por los paramentos exteriores realizada por García de Viedma, M. en un edificio demostrador en el centro histórico de Zaragoza del proyecto LIFE (1) y en el interior de una vivienda durante un proceso de depresión (2).

Fuente: Elaboración propia dentro del proyecto LIFE 10 ENV/ES/439. condiciones bioclimáticas como parte de las condiciones que habrán de cumplir los edificios para ser autorizados es una práctica que puede generar grandes beneficios a los usuarios. Son notables las directivas que, en este sentido, promulga la Comisión Europea y su reflejo en algunas normativas urbanísticas. Por ejemplo, la que está en vigor para el centro de Málaga, que exige sombrear los huecos en las envolventes 0 las normas voluntarias establecidas para la Comunidad de Madrid dan directrices muy claras para el ahorro de energía en la climatización. Para ello, es imprescindible, más allá de simular comportamientos futuros, comprobar la repercusión sobre el consumo y las condiciones de confort, tanto en el interior de los edificios como en su exterior, en condiciones reales de uso En este sentido, se ha detectado que los errores en el establecimiento de los climas de referencia han sido, en ocasiones, una fuente de errores de prescripción y peritación de la respuesta de los edificios al clima. Así, la reciente modificación de los climas de referencia para las Islas Canarias en España ha 
venido a corregir los incrementos de temperatura producidos en verano y la necesidad de aportar aire frio en aquellos edificios a los que la legislación obligaba a disponer más aislamiento térmico del adecuado.

En climas templados tiene especial influencia la reducción de la demanda basada exclusivamente en la estanqueidad que ha conducido históricamente a patologías descritas como "síndrome del edificio enfermo". Actualmente, en Europa, las directivas han incorporado sistemas de ventilación mecánica y natural forzada que permiten el uso de filtros y sistemas de control automatizado de indudable utilidad en zonas con una alta contaminación del aire exterior. Será necesario comprobar hasta qué punto los sobrecostes que exigen, su consumo de energía y su mantenimiento continuo permiten una adecuada calidad del aire interior en otras localizaciones. La consideración, por ejemplo, de ventilaciones discontinuas, frente a la continua por la que se aboga en la actualidad, permitiría aprovechar las oportunidades que nos da el clima para ventilar solo cuando las condiciones exteriores son más favorables.

\section{Condiciones de uso}

Tradicionalmente, los usuarios han fijado su residencia en la ubicación más apropiada a sus demandas. Cuando les ha sido posible, se han desplazado para eludir periodos de excesivo calor o frío, ocupado solanas o umbrías según la estación, clausurado 0 acondicionado estancias diferentes para el día y la noche 0 en los periodos cálidos y fríos o han cambiado la configuración de los elementos de protección, modulado la ventilación o modificado la humedad del ambiente.

En definitiva, basándose en su experiencia sobre las prestaciones de los espacios, la participación activa ha sido un componente más del acondicionamiento bioclimático. El conocimiento de las condiciones climáticas exteriores y de la respuesta de los edificios es determinante para establecer cuando se deben aplicar las estrategias de climatización y adoptarse medidas de control o acondicionamiento higrotérmico. Algunas, como la ventilación y la ocultación, pueden activarse a voluntad del usuario. Estas son dos estrategias de climatización sencillas y gratuitas de enorme potencial en la arquitectura bioclimática. Asimismo, estas tradicionalmente son realizadas con un accionamiento manual por los usuarios basándose en su experiencia personal y su aprendizaje colectivo, por lo que, actualmente, son susceptibles de ser automatizadas. Otras requieren anticipar las condiciones climáticas, ya que no pueden ser alteradas fácilmente, como la inercia, la exposición o la puesta en servicio de los equipos de funcionamiento diferido o inerciales.

En este sentido, ha resultado útil la elaboración de climas de referencia formados con las medias móviles en periodos que oscilan entre un día y unas semanas, para establecer el momento en que la reacción del edificio habrá de ser apoyada con sistemas complementarios de captación o disipación de energía. Sin embargo, probablemente el aspecto más importante que se debe controlar en la edificación es la contaminación, tanto la producida en el interior como en el exterior, ya que, actualmente, la contaminación (polución) del aire es una de las principales causas de morbilidad y mortalidad. Esto justifica una modificación de su definición para Europa y en 1968 la amplificación de su divulgación más allá de la órbita científica (Chovin \& Roussel, 1986).

\section{Conclusiones}

Durante muchos milenios, la arquitectura ha conseguido, gracias a la amplia experiencia acumulada y al poderoso aparato tecnológico que se ha construido en estas últimas décadas en el campo de la edificación, una notable adaptación al clima mediante el empleo de los materiales, técnicas y diseños que la tradición nos ha legado, permitiendo la incorporación de mejoras progresivamente más complejas. Actualmente, se exige que se anticipen las prestaciones y el rendimiento de los edificios antes de su puesta en obra, considerando una mala praxis las correcciones posteriores que incrementan el coste y retrasan la puesta en servicio. Para ello, la administración pública ha establecido 
garantías mediante procedimientos de regulación prescriptivos, prestacionales o mixtos que han de acreditarse antes y, a veces también, después de su construcción.

El éxito de este proceso está actualmente limitado por un avance muy asimétrico entre la gran capacidad de peritación informática y la incorporación en ella del actual conocimiento de los materiales, el comportamiento físico de la transferencia de calor, las condiciones atmosféricas reales en las que los edificios se insertan, las condiciones de confort adaptativo que son adecuadas para sus usuarios y del aprovechamiento de la capacidad de intercambiar energía de libre disposición con el entorno. El desarrollo del análisis bioclimático y su efectiva incorporación a los procedimientos con los que se anticipa y controla la respuesta de los edificios al clima y su adaptación a las necesidades que se les demandan, sugiriere las siguientes líneas de acción:

1. El estudio de la arquitectura tradicional que, avalada por la experiencia, ha llegado hasta nuestros días, mediante la aplicación de procedimientos de análisis numérico y predictivo, empleándola para validar las herramientas de simulación que actualmente están en desarrollo.

2. Definir con más precisión el clima donde se ubican los edificios, especialmente mediante el establecimiento del microclima de proximidad, ajustado a cada ubicación y tipología arquitectónica, y definiendo las franjas de homogeneidad térmica y los periodos en que estas se producen.

3. Avanzar en el estudio de las condiciones de confort, entendidas como un indicador formado por diversas variables interconectadas, que no pueden ser ajenas a las condiciones culturales, socioeconómicas y metabólicas de la población a la que se aplica.

4. Elaboración de catálogos de materiales, sistemas y elementos constructivos que recojan las cualidades de los productos en su aplicación al análisis bioclimático de la arquitectura.

5. Instruir los procesos de diseño y prescripción arquitectónica con catálogos de estrategias bioclimáticas, complementadas con procedimientos de adaptación, socioeconómica o cultural. Considerando su compatibilidad y su capacidad de ser activadas o desactivadas en función del uso y las condiciones ambientales.

6. Realizar pruebas "in situ" del desempeño, comprobando que la ejecución y las prestaciones son las prescritas. Disponer sistemas de toma de datos que permitan la supervisión del proceso y el establecimiento de protocolos que anticipen el estado del edificio y maximicen su eficacia.

7. Analizar la eficacia de las combinaciones de estrategias bioclimáticas en periodos con condiciones climáticas homogéneas y, de esta forma, valorar su influencia global y las diversas opciones de accionamiento o desactivación.

8. La normativa debe proteger al usuario exigiendo que la promoción inmobiliaria le provea de confort con el menor coste económico y medioambiental posible, con la consideración de las condiciones de soleamiento, ventilación, aislamiento, volumen interior o inercia térmica apropiadas a cada lugar.

9. Las adaptaciones del edificio a las condiciones de uso deben instruirse o automatizarse desde el conocimiento de los sistemas y estrategias bioclimáticas, limitando la contaminación provocada para conseguirlo.

En definitiva, se considera que la adopción de análisis bioclimáticos y la prescripción basada en ellos exige afianzar nuestro conocimiento en las áreas indicadas para que, efectivamente, colabore en la mejora del desempeño ambiental de la edificación. 


\section{Referencias bibliográficas}

AEMET. (2015). Informe climático del año 2014. Serie de temperaturas medias anuales (1961-2014). Recuperado de http://www.aemet.es/documentos/es/ serviciosclimaticos/vigilancia_clima/resumenes_climat/anuales/res_anual_ clim_2014.pdf

Alberti, L.B. (1582). Los diez libros de Architectura. Madrid: Bibliotheca Regia Monacensis. Recuperado de http://mdz-nbn-resolving.de/urn:nbn:de:bvb:12-bsb10150247-7

Allen, E. (Ed). (1978). La casa "otra". La autoconstrucción según el MIT. Barcelona: Editorial Gustavo Gili S.A.

Almorox Alonso, J. et al. (2004). Metodología para la elaboración de estudios aplicados de climatología. Madrid: UPM.ETSIA Departamento de Edafología.

Bardou, P. \& Arzoumanian, V. (1981). Sol y arquitectura. Barcelona: Editorial Gustavo Gili S.A.

Bedoya, C \& Neila, F.J. (1986). Acondicionamiento y energía solar en arquitectura. Madrid: UPM. ETSAM

Butti, K. \& Perlin J. (1985). Un hilo dorado. 2500 años de arquitectura y tecnología solar. Madrid: Hermann Blume.

Centnerova, L. \& Hensen, J.L.M. (2001). Energy and indoor temperature consequences of adaptive thermal comfort standards. Energy. Recuperado de http://citeseerx.ist. psu.edu/viewdoc/download?doi=10.1.1.513.59\&rep=rep1\&type=pdf

Chovin, P. \& Roussel, A. (1986). La polución atmosférica. Barcelona: Ediciones Orbis S.A.

Cuhna, L.V. (1988). A first time experiment in Portugal. The crato town school building a bioclimatic approach. Lisboa: Ministerio da educaçao e cultura.

Esteban Saiz, J. L. (1986). La arquitectura popular como base de una arquitectura bioclimática. Aplicación al enfriamiento pasivo. Informes de la Construcción, 38, (385), 59-69.

Fanger, P. O. (1970). Thermal comfort. Copenhagen: Danish Technical Press.

Fernández García, F. (1996). Manual de climatología aplicada. Clima, medio ambiente y planificación. Madrid: Editorial Síntesis S.A.

García Arroyo, A. (Ed). (1983). Bases para el diseño solar pasivo. Madrid: IETCC CSIC.

Gil Olcina, A. \& Olcina Cantos, J. (1999). Climatología básica. Barcelona: Ariel Geografía.

Givoni B, A. (1969). Man, Climate and Architecture. London: Elsevier Architectural Science Series.

Godoy Muñoz, A. (2012). El confort térmico adaptativo. Aplicación en la edificación en España [Trabajo final de maestría). Máster en Sostenibilidad UPC.

Harari, Y.N. (2014). Sapiens. Madrid: Debate.

Holdridge, L.R. (2000). Ecología basada en zonas de vida. San José: Instituto interamericano de cooperación para la agricultura.

Hyde, R. (2000). Climate responsive design. London: E Et FN Spon.

Johnston, D. \& Gibson, S. (2011). Green from the ground up. Sustainable, healthy, and energy-efficient home construction. Newtown: The Taunton Press.

Koenigsberger, O.H., Ingersoll, T.G., Mayhew, A., Szokolay, S.V. (1977). Viviendas y edificios en zonas cálidas y tropicales. Madrid: Paraninfo S.A.

Lewis, O \& Goulding, J. (Eds.). (1966). European directory of sustainable \& energy building 1966 Components-services -materials. London: James\& James (science publishers) Ltd.

Lewis, O (1987 a 1989). Proyect Monitor Commission of the European communities. Dublin: University College Dublin. 
Lewis, O.J. \& Brophy, V. (2011). A green Vitruvius principles and practice sustainable architectural design. London: Earthscan.

Lorente, J.M. (1930). Meteorología. Barcelona: Labor S.A.

Luxan, M. et al. (2010). Habitar sostenible. Integración ambiental de 15 ejemplos de arquitectura popular española. Madrid: Ministerio de Obras Públicas y Urbanismo.

Mazria, Edward. (1979). The Passive Solar Energy Book. Danvers: Rodale Press.

Moita, F. (1988). Energia solar passiva 1 y 2. Lisboa: Direcçao-Geral De Energía Impresa Nacional Casa Da Moeda.

Neila, F.J. (2000a). La acumulación de las energías renovables (1) La inercia y la estabilidad térmica en las construcciones. Madrid: UPM. ETSAM. Cuadernos del Instituto Juan de Herrera.

Neila, F.J. (2000b). El soleamiento del edificio (II) Métodos para el dimensionado de protecciones solares. Madrid: UPM.ETSAM. Cuadernos del Instituto Juan de Herrera.

Neila, F.J. (2004). Arquitectura bioclimática en un entorno sostenible. Madrid: Munilla Leira.

Öhmann, C. (2014). Measurement in termography Täby. Sweden: Flir Systems and Infrared Training Center.

Olcina Cantos, J. (2006a). Riesgos Naturales I, Sequias e Inundaciones. Barcelona: Davinci Continental S. L.

Olcina Cantos, J. (2006b). Riesgos Naturales II, Huracanes, Sismicidad y Temporales. Barcelona: Davinci Continental S. L.

Olgyay, V. (1998). Arquitectura y Clima. Barcelona: Editorial Gustavo Gili.

Oliver, P. (Ed). (1978). Cobijo y sociedad. Madrid: H. Blume Ediciones.

Oger, R., Buffet, D. \& Kestemont, M. (2005). Estimation of leaf wetness duration using standard weather station data and radar images to assess the risk of wheat contamination by mycotoxins at regional scale in Belgium. In Maracchi, G. \& Bogatag, K. (Eds.), Leaf wetness duration: Analysis of the agrometeorological requirements and evaluation of new estimation methods (Cost Actions 718) (pp. 41-51). Bruselas: European Comission.

Palladio, A. (1797). Los Cuatro Libros de Arquitectura. Traducidos e ilustrados con notas por Don Joseph Francisco Ortiz y Sanz. Madrid: Imprenta Real. Recuperado de: http://www.sedhc.es/biblioteca/tratado.php?ID_pubD=19

Porto, M. (Ed.). (2013). Implementing the energy performance of buildings directive (EPBD) Featuring country reports 2012. Concerto action energy performance of buildings. Porto: ADENE.

Rico Delgado, F. (2009) Modelo de diagnóstico por imagines en edificación mediante la aplicación de tecnologías avanzadas [Tesis doctoral]. Sevilla: Universidad de Sevilla.

Roaf, S., Fuentes, M. \& Thomas, S. (2010). Ecohouse Oxford: Architectural Press.

Sevilla, A. (2000). Manual arquitectura solar para climas cálidos. GEOHABITAT.

Steedmann, P. (1978). Energía medioambiente y edificación. Madrid: Blume ediciones.

Szokolay, S.V. (1975). Solar energy and building. London: The Architectural Press.

Szokolay, S.V. (2008). Introduction to architectural science. The basis of sustainable design. New York: Elsevier

The American Institute of Architects. (1984). La casa pasiva, clima y ahorro energético. Madrid: Hermann Blume.

Vitruvio, M. (1786). Los diez libros De architectura traducido por Don Joseph Ortiz y Sanz. Madrid: Imprenta Real. Recuperado de: http://bdh-rd.bne.es/viewer. vm?id=0000012956\&page $=1$

Vollmer, M. \& Möllmann, K. P. (2010). Infrared thermal imaging. Fundamentals, research and applications. Weinheim: Wiley-vch Verlag GmbH \& Co KGaA. 
Watson, D. (1985). La casa sola. Diseño y construcción. Madrid: Hermann Blume.

Wooley, T., Kimmins, S., Harrison, P. \& Harrison, R. (1997). Green Building Hondbook. London: E\& FN SPON.

Yañez, G. (1988). Arquitectura solar. Aspectos pasivos, bioclimatismo e iluminación natural. Madrid: MOPU.

Yañez, G. (1982). Energía Solar, edificación y clima I y II. Madrid: Ministerio de Obras públicas y urbanismo.

Yañez, G. (1976). La energía solar en la edificación. Madrid: Ministerio De La Vivienda. 